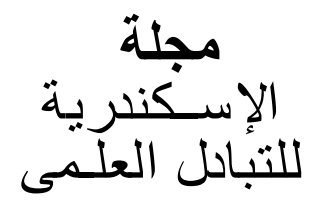

أبريل - - Vيونيو

بملد بملد

تطبيت أسلوب التطريز اليدوي Hardanger علي بعض المفروشات وتصميم وتنفيذ و تقييم برنامج تدريبي علي هذا الأسلوب من التطريز لعينة من المدربات بمدينة الاسكندرية

$$
\text { عزة إبراهيم على وصفية عبد العزيز ساروخ ' ، أنعام السيد أبو زيدجا }
$$

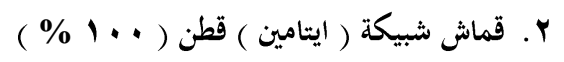

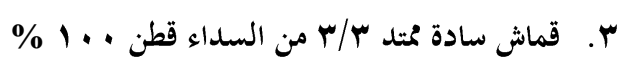

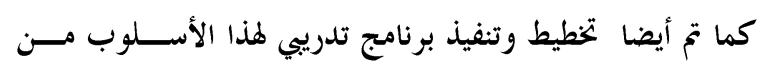
التطريز لعينة من المدربات العاملات في مجال التدريب علي الصناعات

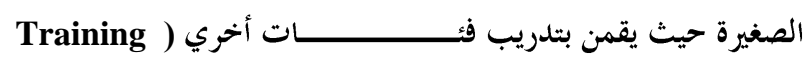

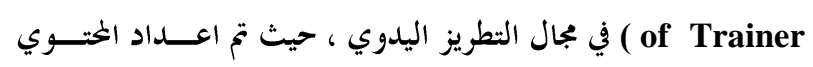
المناسب من الوحدات التعليمية وتم تنفيذ البرنامج لمدة شهرين بعمدل

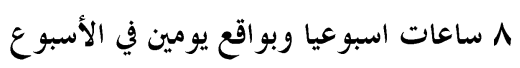

$$
\begin{aligned}
& \text { وقد اشارت نتائج الدراسة الي : }
\end{aligned}
$$

أولا : نتائج تحكيم النماذج المطرزة بأسلوب Hardanger أ- بالنسبة للمفرش :

أوضحت نتائج تحليل التباين بين بنود تحكيم مظهريسـة النمـــاذج

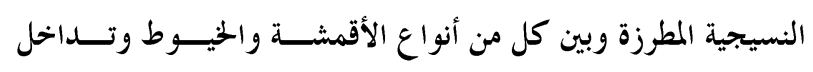

$$
\text { الأقمشة والخيوط معا أن : }
$$

تأثير الأقمشة معنويا بالنسبة لملائمة غـــرزة التطريــز للتركيــبـ النسجي ونوع القماش وجودة التطريز والناحية الجمالية للشكل

$$
\text { النهائي وذلك عند مستوي معنوي } 1 \text { + , . }
$$

• أثير الخيوط معنويا بالنسبة لملائمة خيط التطريز المستخدم للقماش في وجودة التطريز والناحية الجمالية للشكل النهائي وذلك عنــــ

$$
\text { مستوي معنوية (†, • م }
$$

\section{الملنخص العربى}

استهدفت هذه الدراسة بصورة رئيسية احياء تراث فن التطريــز المعروف باسم hardanger كأحد اساليب التطريز اليدوي وذلــك لاستخدامه والاستفادة منه في بعض المنتجات النسيحية المعتمدة علــي تلك التقنية مثل المفروشات ( مفرش- ستارة ) بالاضافة الي تصــميم

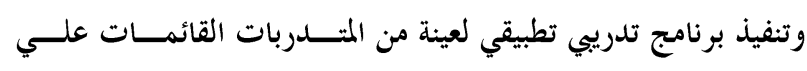

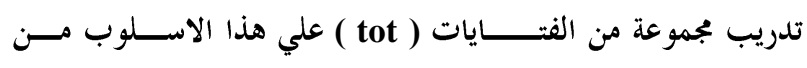
التطريز وقد تم اجراء دراسة تطبيقية من خلال اعداد ناذج باستخدام هذا الاسلوب من التطريز تحتوي علي بعض الوحدات الزخرفية المناسبة ثم

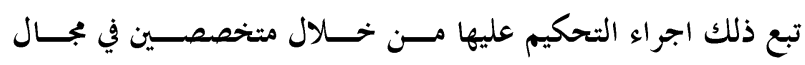
المنسوجات والملابس بصفة عامة ومتخصصين في التطريز بصفة خحاصة

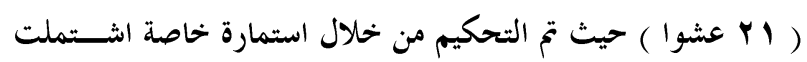
علي (V) بنود تغطي جوانب الدراسة ثت تم التقييم بإعطاء درجة مــن

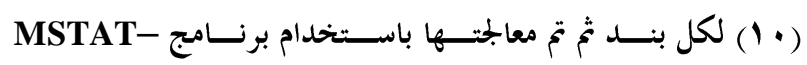
C(1999) أ- الخحيوط المستخدمة : تم اســـخدام خيــوط الكتــون برليـهـ، السولافابل، المالونية. ب- الأقمشة المستخدمة حيث تم استخدام

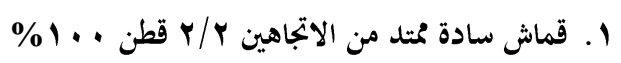

$$
\begin{aligned}
& \text { ا قسم الاقتصاد المتزلي - كلية الزراعة - جامعة الإسكندرية }
\end{aligned}
$$

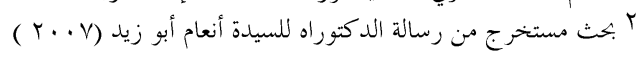

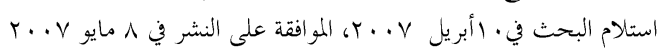


التقييم

عن تاثير تداخل الاقمشة والحيوط معا حصل القمــاش الســادة

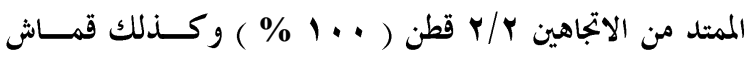

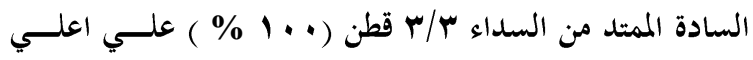

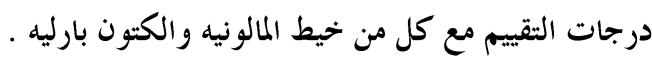

Hardanger ثانيا : نتائج البرنامج الثدريب الثدريب التطبيقي لفن التطريز أظهرت نتائج البرنامج التدريبي التطبيقي ان :

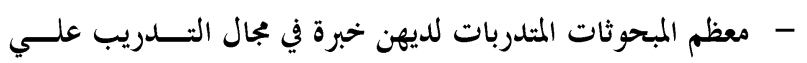
الصناعات الصغيرة من سنة الي خمس سنوات . - كل كل المبحوثات تقريبا لم يحصلن علي دورات تدريبية في التطريسـز اليدوي .

- تغيرت معلومات المبحوثات عن فن تطريز hardanger بشــــل ايجابي بعد التدريب حيث لم يكن لديهن فكرة عنه قبل التدريب .

\section{المقدمـــة}

يعد فن التطريز واحدا من أقدم وارقي الفنون وأكثرها جمالا

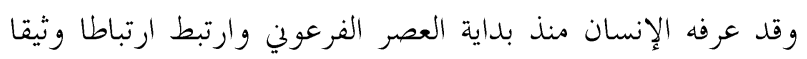
بصناعة الملابس والمفروشات لإثراء القطع المطرزة همدف اضافة قيم جمالية ونفعية اقتصادية ، وقد تطور فن التطريز في شتي صوره سواء

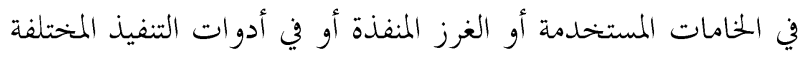
، فقد تحولت الغرز البسيطة والمستخدم لها الخيوط علي النسيج إلي

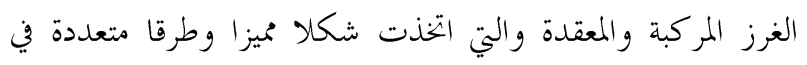
تنفيذها وقد نفذت عدد لا ذائي من الغرز في شكل تكرارات وتنسيقات جمالية كانت غرز التطريز هي المحور الرئيسي هلا (ماجدة

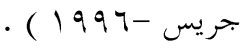

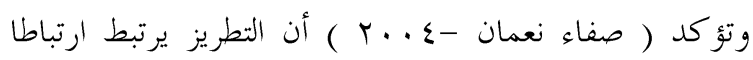

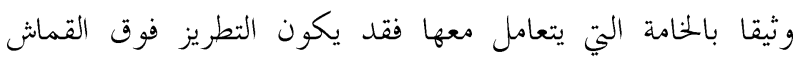

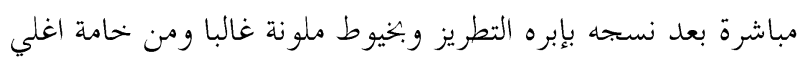

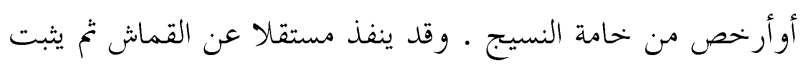

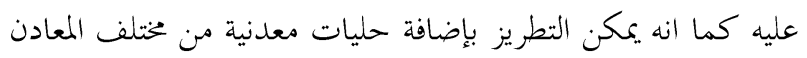
أو الخرز بأشكال متعددة وكذلك استخدام الترتر بألوان وأحجام

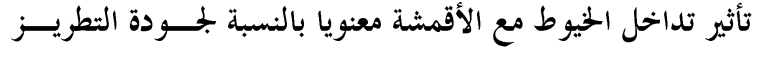
والناحية الجمالية للشكل النهائي عند مستوي معنوية (1 ( • ) . كما أوضحت نتائج اختبار ( t ) بين متوسطات بنــود تحكـيميم

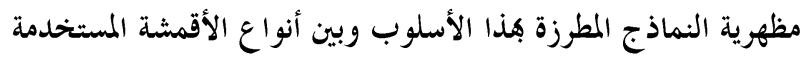

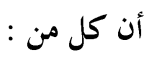

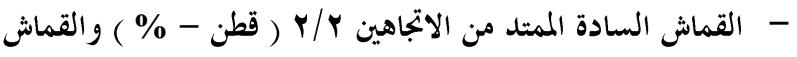

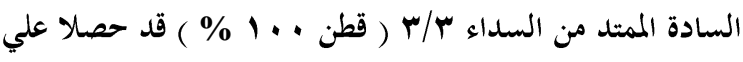

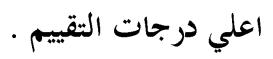

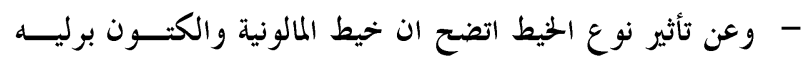
حصلا علي اعلي درجات التقييم . - عن تاثير تداخل الاقمشة والحيوط معا وجد ان القماش الســادة

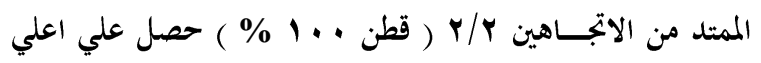

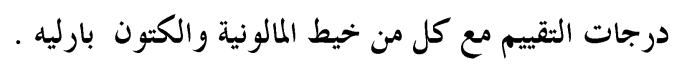
ب- ب بالنسبة للستارة

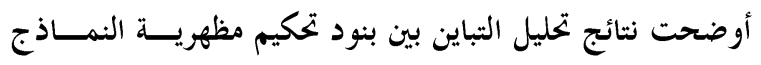

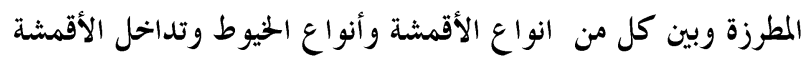

$$
\text { والخيوط معا أن : }
$$

تاثير الاقمشة كان معنويا بالنسبة لملائمة غرزة التطريز للتركيــبـ

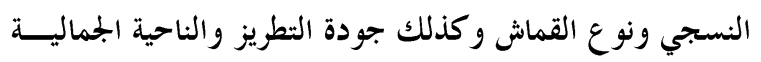

$$
\text { للشكل النهائي وذلك عند مستوي معنوية (1 + , • ) }
$$

تاثير الحخيوط كان معنويا بالنسبة لكل من ملائمة خيط التطريــز

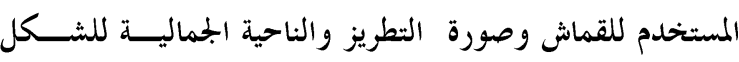

$$
\text { النهائي عند مستوي معنوية ( } 1 \text { ( , • ) ، ( ه •, • ) . }
$$

تاثير تداخل الخيوط والاقمشة كان شديد المعنوية بالنسبة لكل من

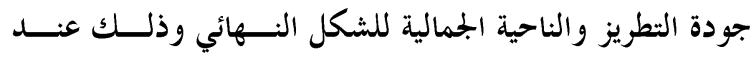

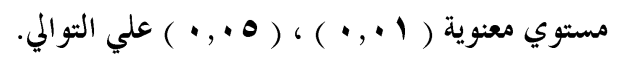

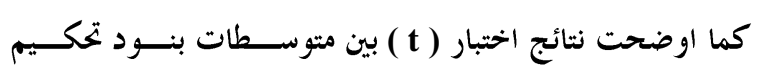

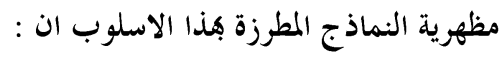

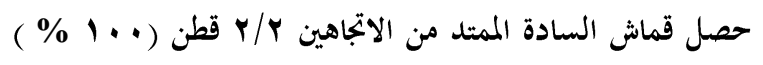

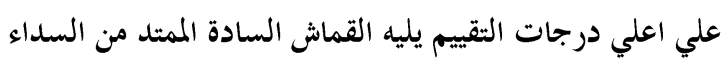
r/r • حصل خيط المالونيه وخيط الكتون بارليه علي اعلي درجات 
وللغرز الداخلية سواء من نفس لون القماش أو ألـــــــــــان أخري (2004-Syliva Muir) )

\section{اهداف الدراسة - 2 - مافة}

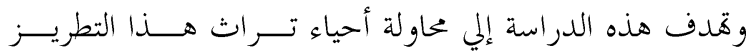

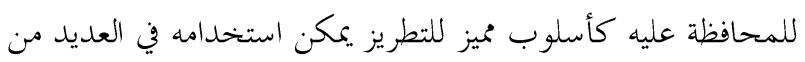

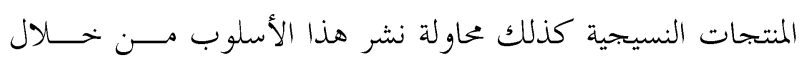

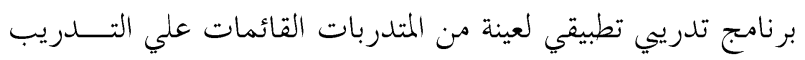

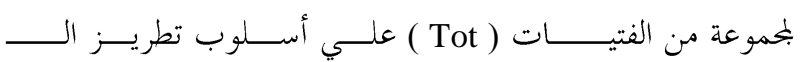
Hardanger وذلك من خلال الأهداف التالية: - تنفيذ بعض النماذج النسجية المطــرزة ( مفــرش - ســتارة )

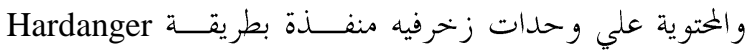

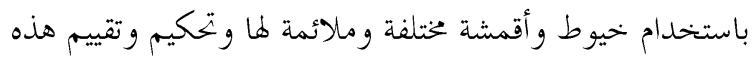

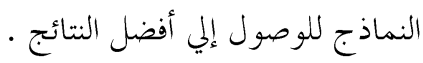

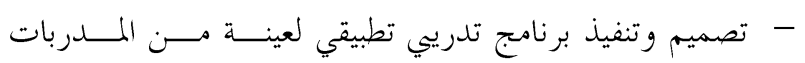

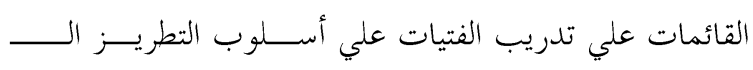
كفئة مستهدفة ( training of Trainer Hanger

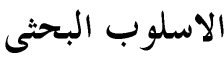

أولا : الدراسة التطبيقية :

\section{ا ـ الأقمشة والخيوط المستخدمة في الدراسة المطيه ل:}

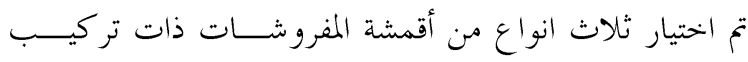
نسجى سادة و كذلك ثلاثة أنواع من الخيوط كالأتي :

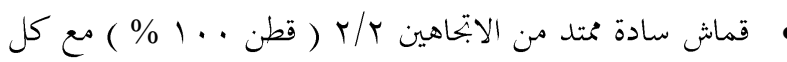
من خيط السولافابل - خيط الكتون بارليه DMC - خــيط

$$
\text { المالونيه DMC }
$$

قماش سادة متد من السداء س/ץ ( قطن . . 1 \% م ) مع كل من خيط السو لافابل - خيط الكتون باريه DMC - خيط المالونية . DMC

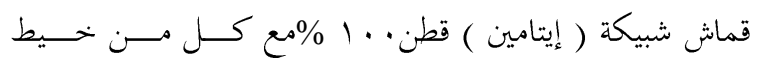

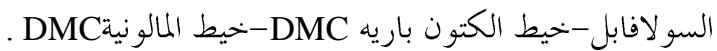
وقد تم تحديد نمرة الخيط وعدد البرمات لخيوط التطريز و كانت
وقد استمر استخدام أنواع محددة من غرز التطريز معروفة وثابتة

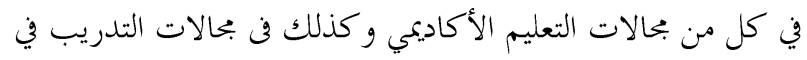

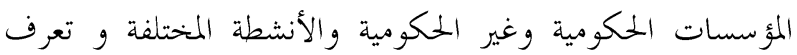

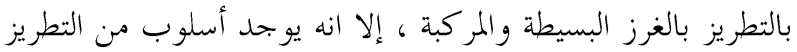
يسمي Hardanger غير مستخدم في أي من البحالات السابقة علي الرغم من انه يعطي تأثيرات جمالية عالية بالإضافة إلي القيمة

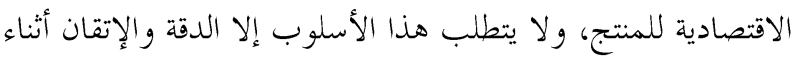
التنفيذ حتى تكون الغرز ملساء غير مشدودة وتقع بداية وهاية

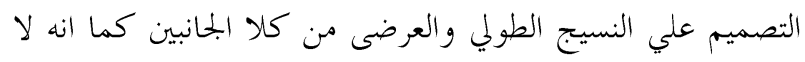
يتطلب الكثير من الخامات والأدوات المساعدة . وتشير Violet m. Endacott 2003 إلى أن بداية هذا النوع من

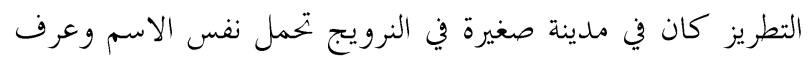

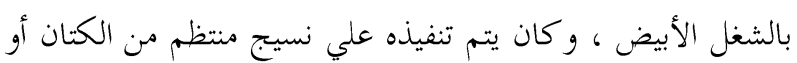
القطن ويطرز بخيوط الكتون بارليه بلون ابيض أو كريمي . ويعرف التطريز Hardanger علي انه طريقة من طرق الفلترية يتم عمله عن طريق تحديد الشكل الخارجي للتصميم بغرزة الخشو

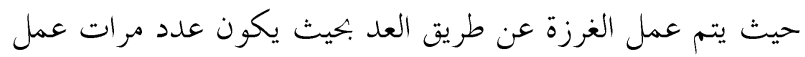
غرزة الحشو متساوي في كل جانب من التصميم ( فاطمة إبراهيم $\cdot(r \cdot r$

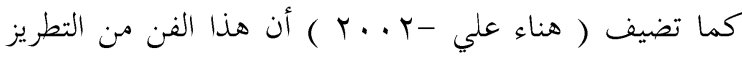
كان سائدا في القرنين السابع عشر و الثامن عشر ورسمي بالشغل الأبيض White Work وكان يتم عمله علي الأقمشة الكتانية وبخاصة ملابس الفلاحين وقد سمي بعد ذلك بالشبكة الصغيرة

. Reticello وعن الأدوات والخامات الملائمة هذا النوع من التطريز فانه

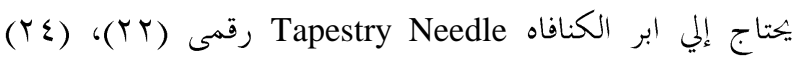

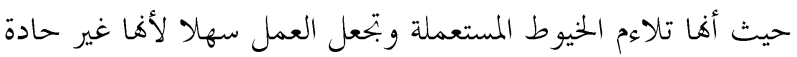
السن .أما عن القماش المناسب فانه يحتاج إلي الأقمشة متساويه

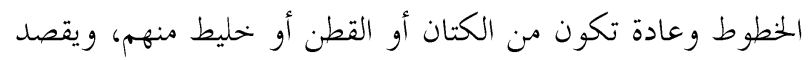

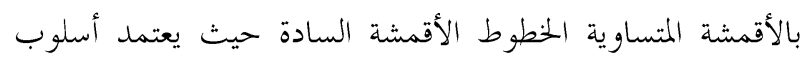

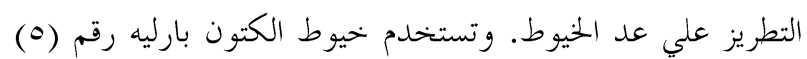
في هذا التطريز للغرزة الخارجية لتصميم الوحدة ، ورقم (م) للحشو 


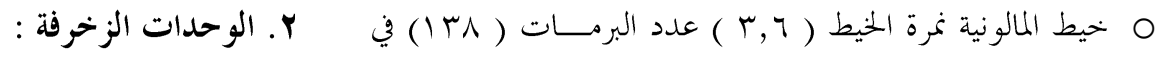

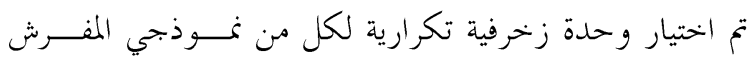

$$
\text { ابتحاه برم z }
$$

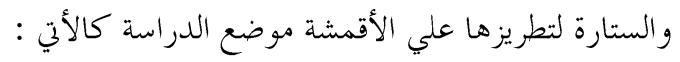

$$
\begin{aligned}
& \text { ع.الأدوات المستخدمة : } \\
& \text { تمثلت الأدوات المستخدمة في كل من الإبر- الإطار- مقص } \\
& \text { صغير ذو طرف حاد مدبب-قمع خياطة - ملقاط . }
\end{aligned}
$$

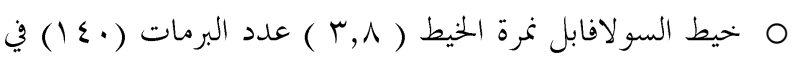

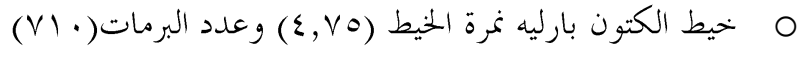

$$
\text { في الابتحاه }
$$

وقد تم استخدام الأنواع السابقة لكل من نماذج المفرش والستارة. يوضح شكل ا ـ خطوات تنفيذ الوحدة التكرارية للمفرش .

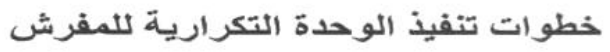

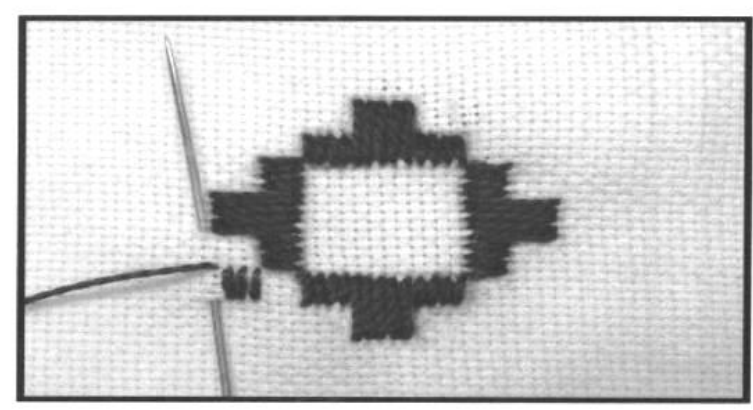

(r) الخطوة

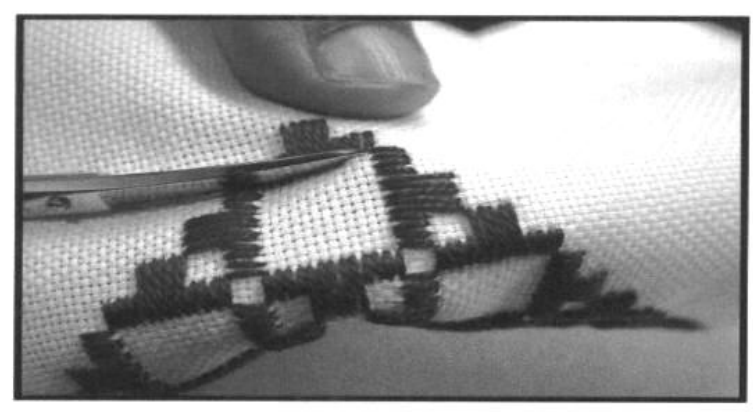

الخطوة (ع)

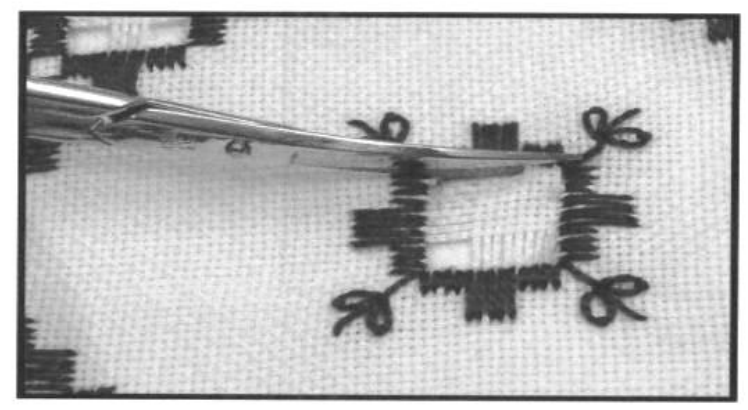

(7) الخطوة

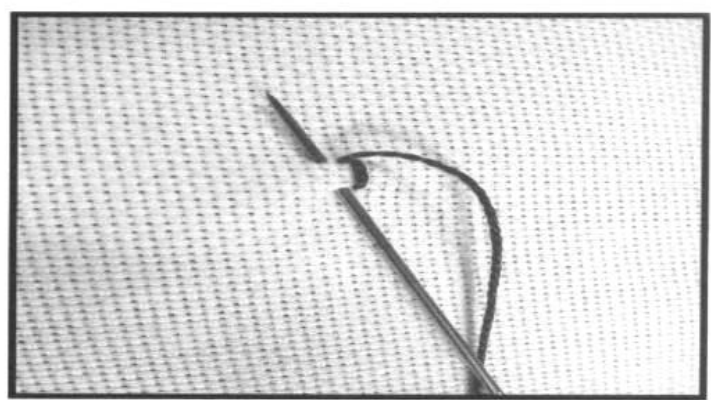

الخطوة (1)

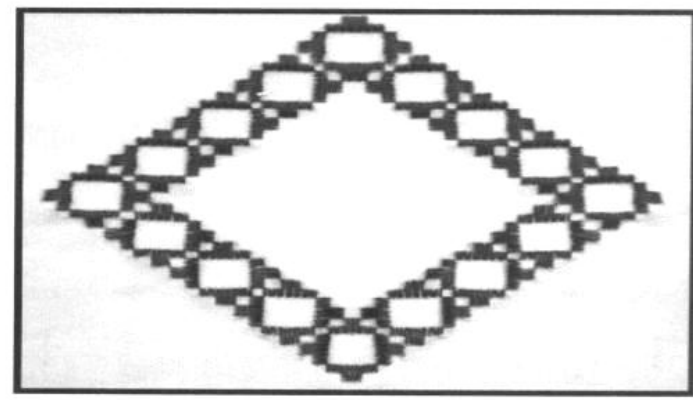

(r) الخطوة

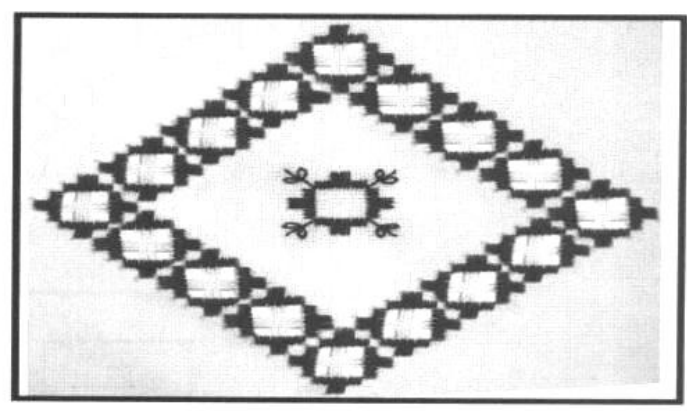

الخطوة (0) 


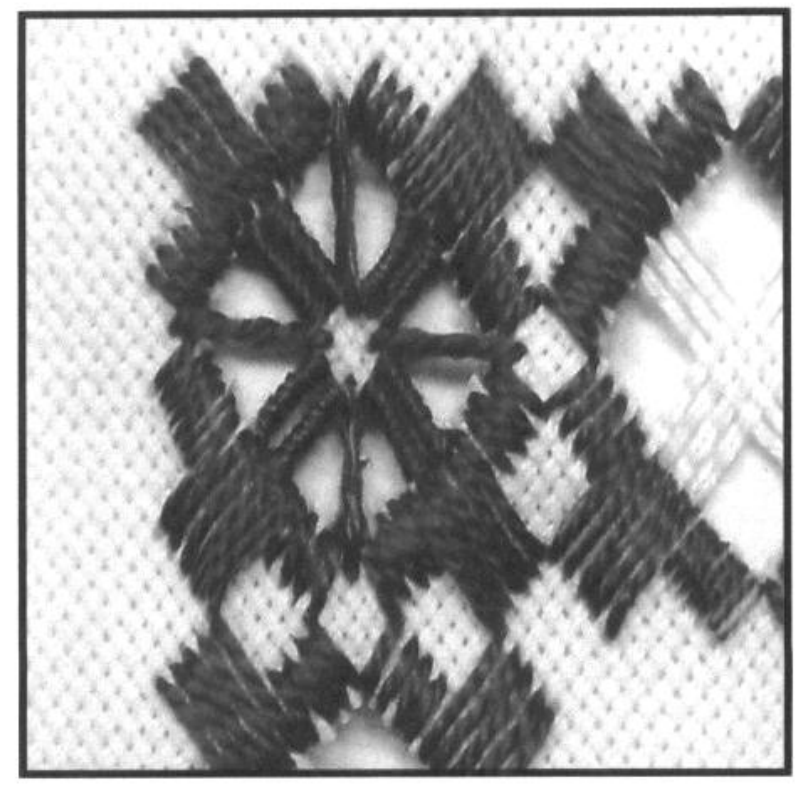

الخطوة (^)

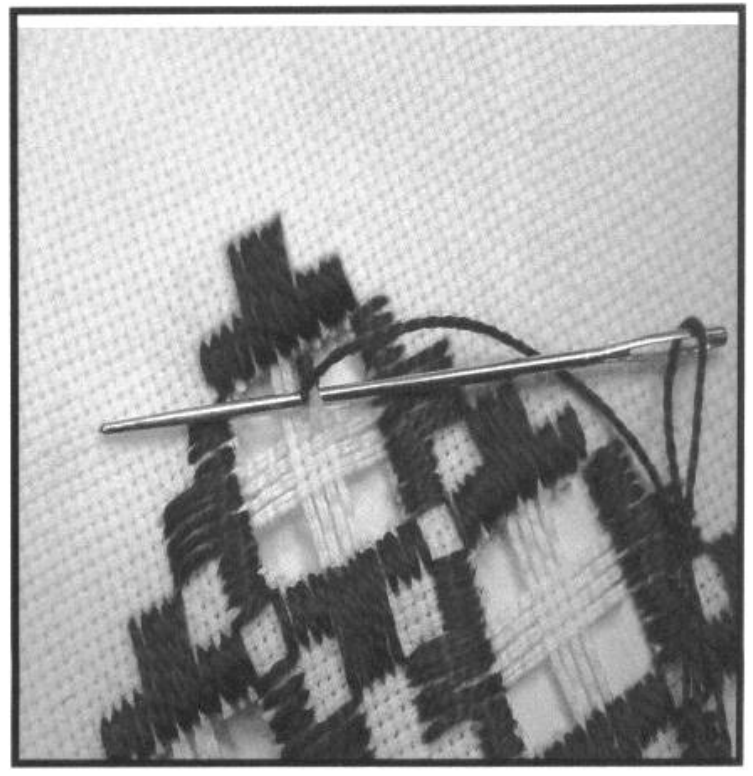

(V) الخطوة

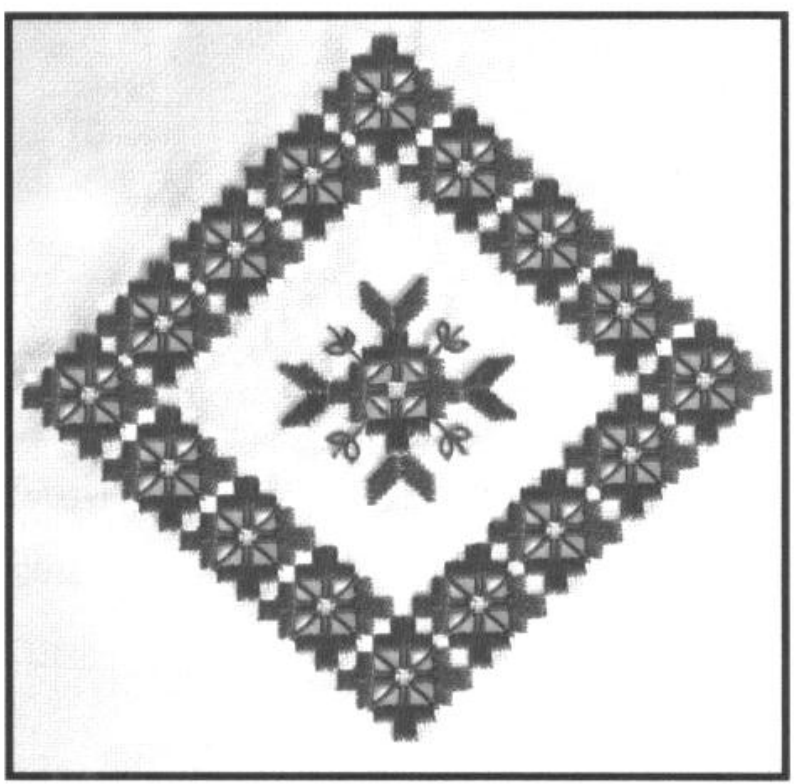

(9) (9) (9) (9) 
يوضح شكل r. خطوات تنفيذ الوحدة التكرارية للستارة .

خطوات تتفيذ الوحدة التكرارية للستارة

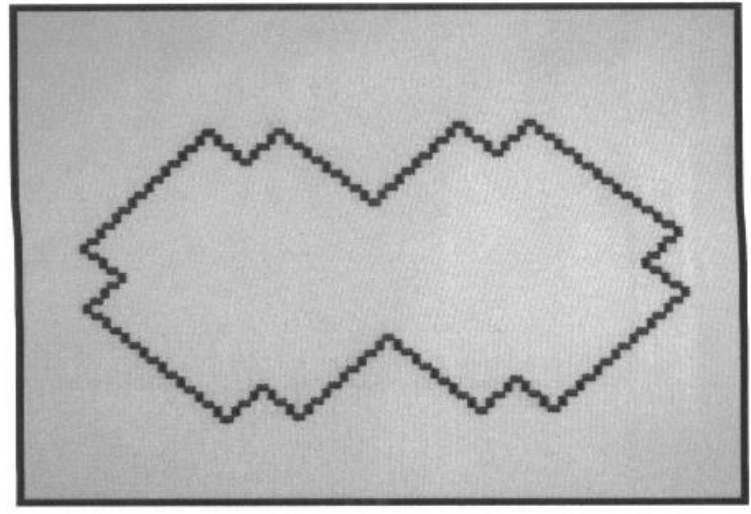

الخطوة (r)

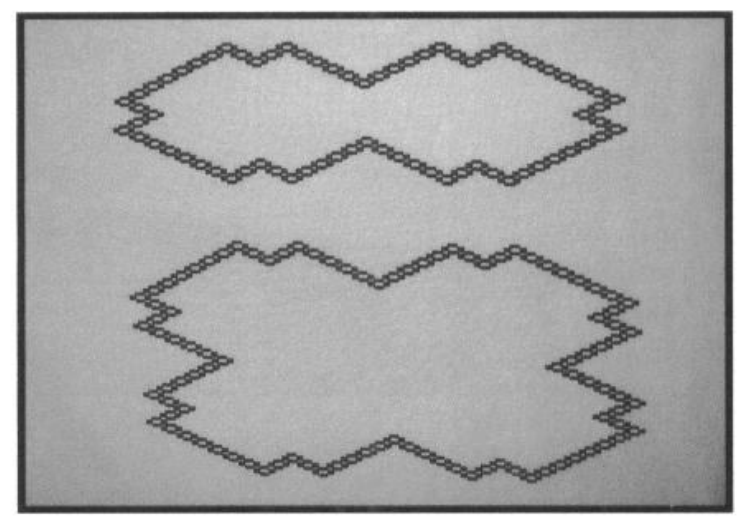

(乏) الخطوة

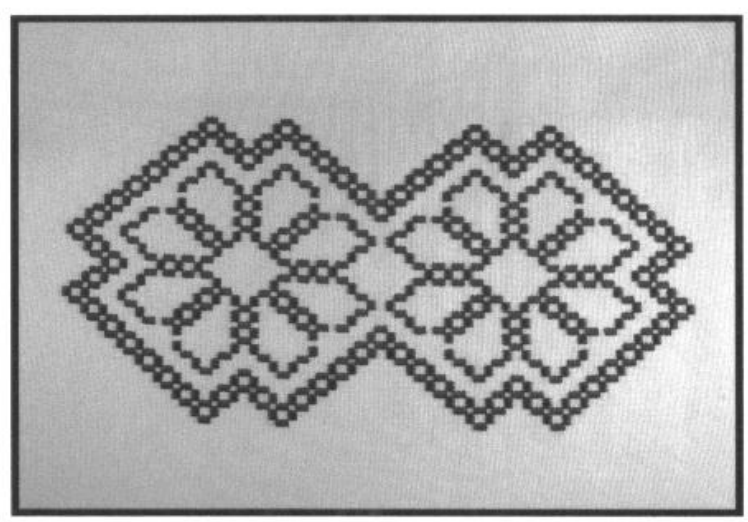

الخطوة (7)

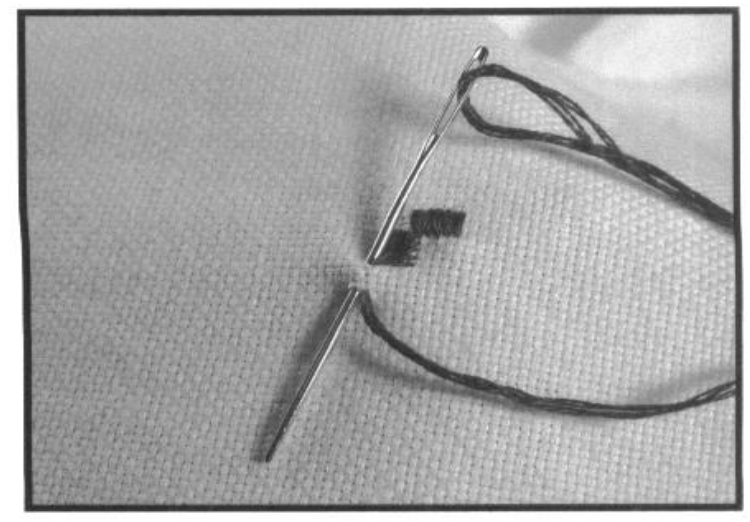

الخطوة (1)

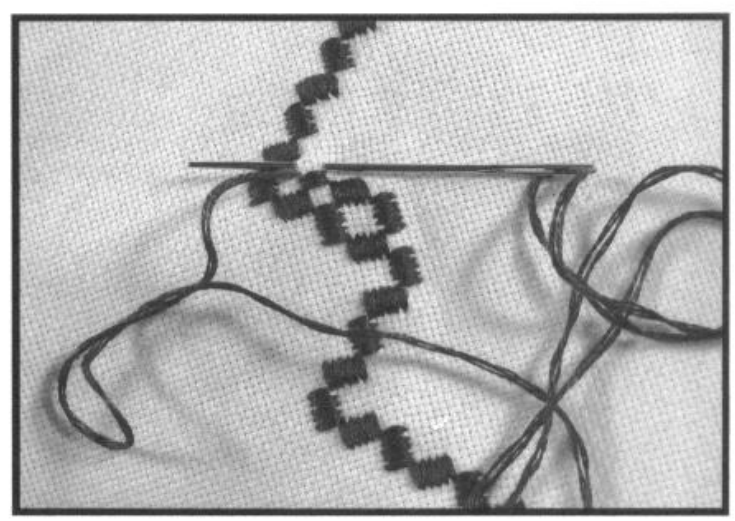

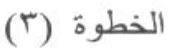

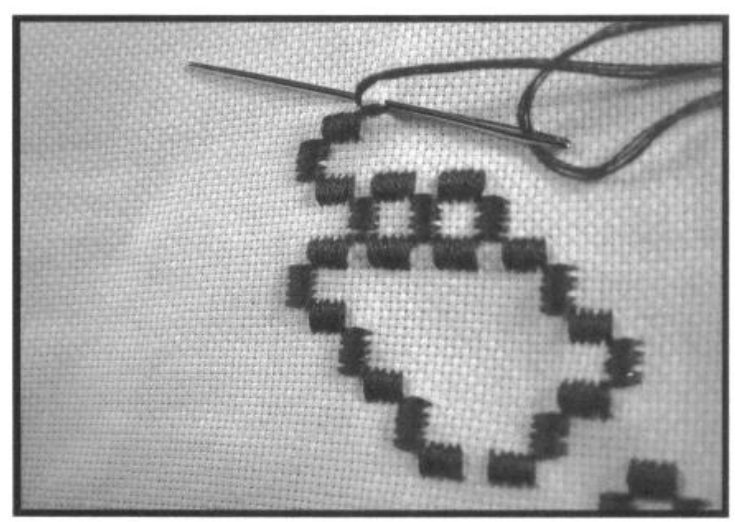

(0) الخطوة 


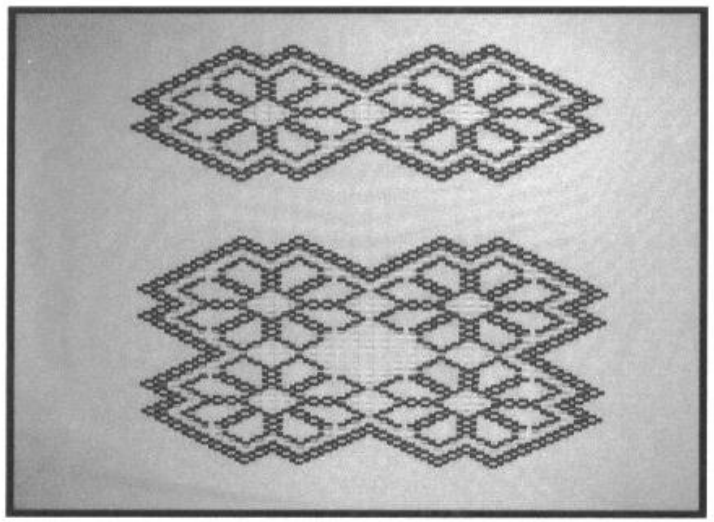

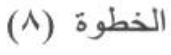

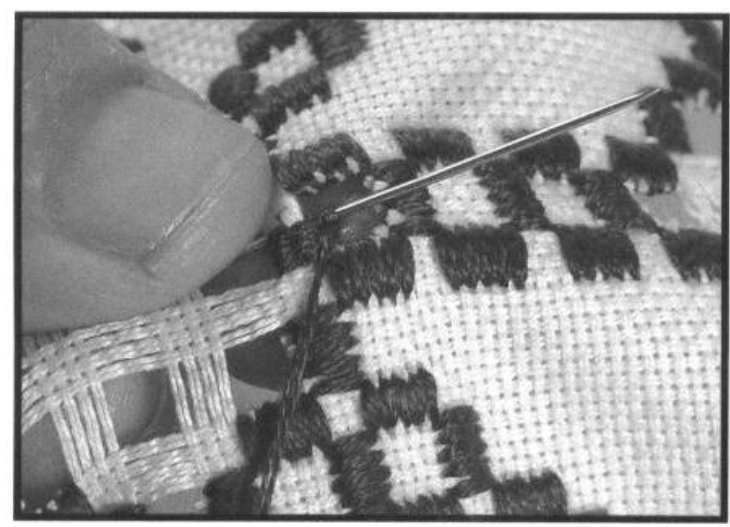

(1. (1) (1) (1) (1)

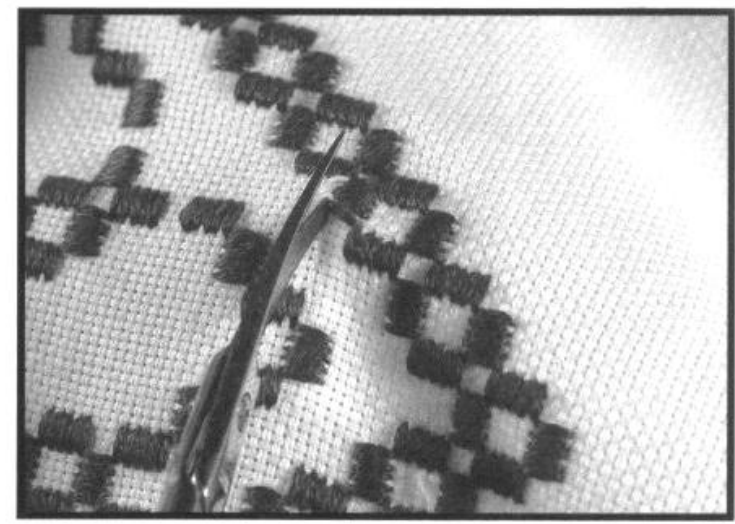

(V) ( الخطوة

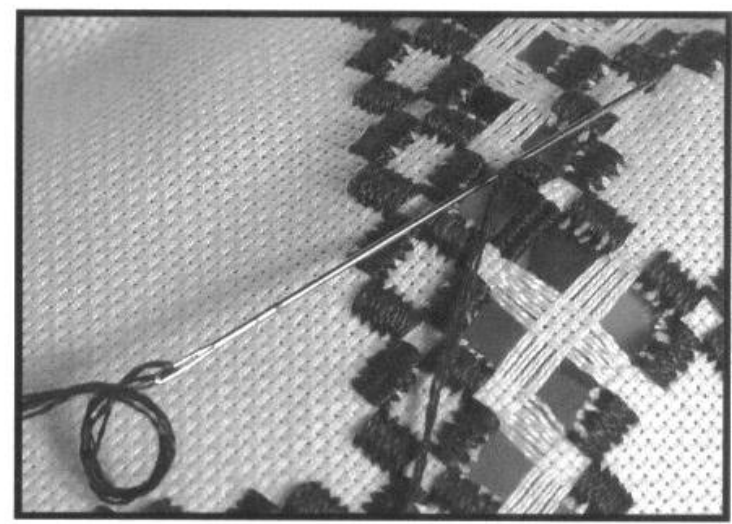

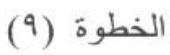

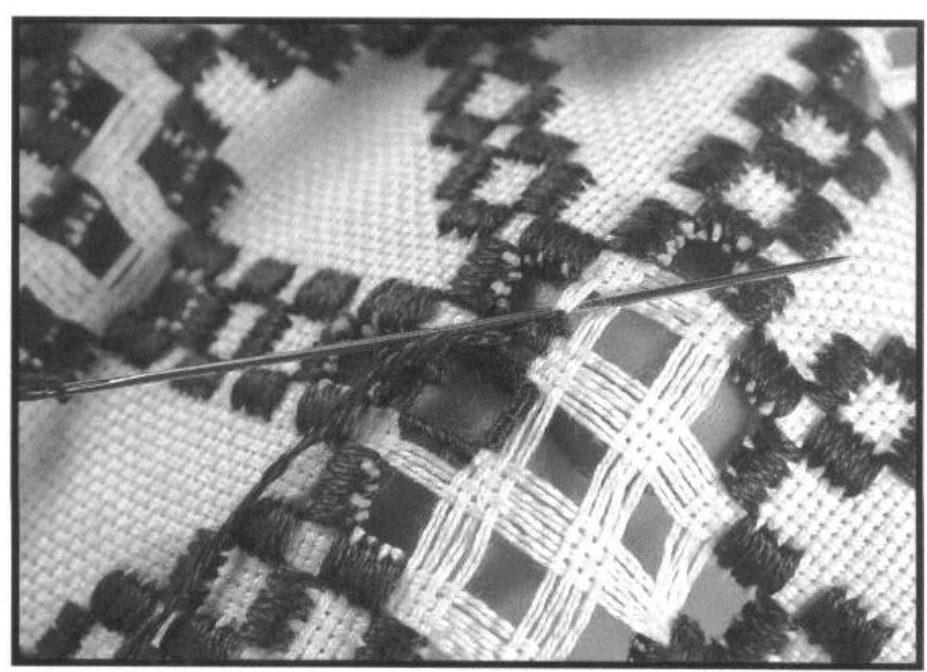

(1) (1) (الخطوة 


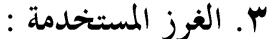

$$
\begin{aligned}
& \text { يوضح الشكل رقم ب ـ أسماء وأنواع الغرز المستخدمة في النماذج . } \\
& \text { اـ غززة السائان: Satin stitch }
\end{aligned}
$$

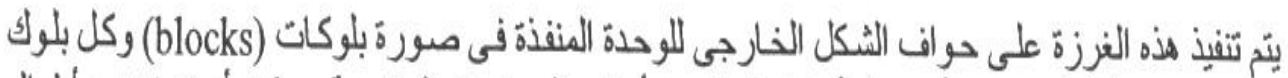

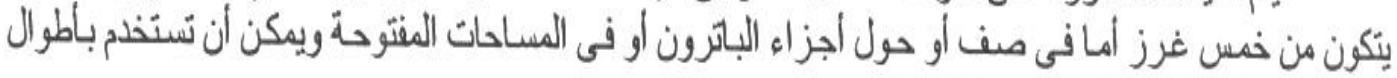

واتجاهات مختلفة لزخرفة التطريز شكل (1)
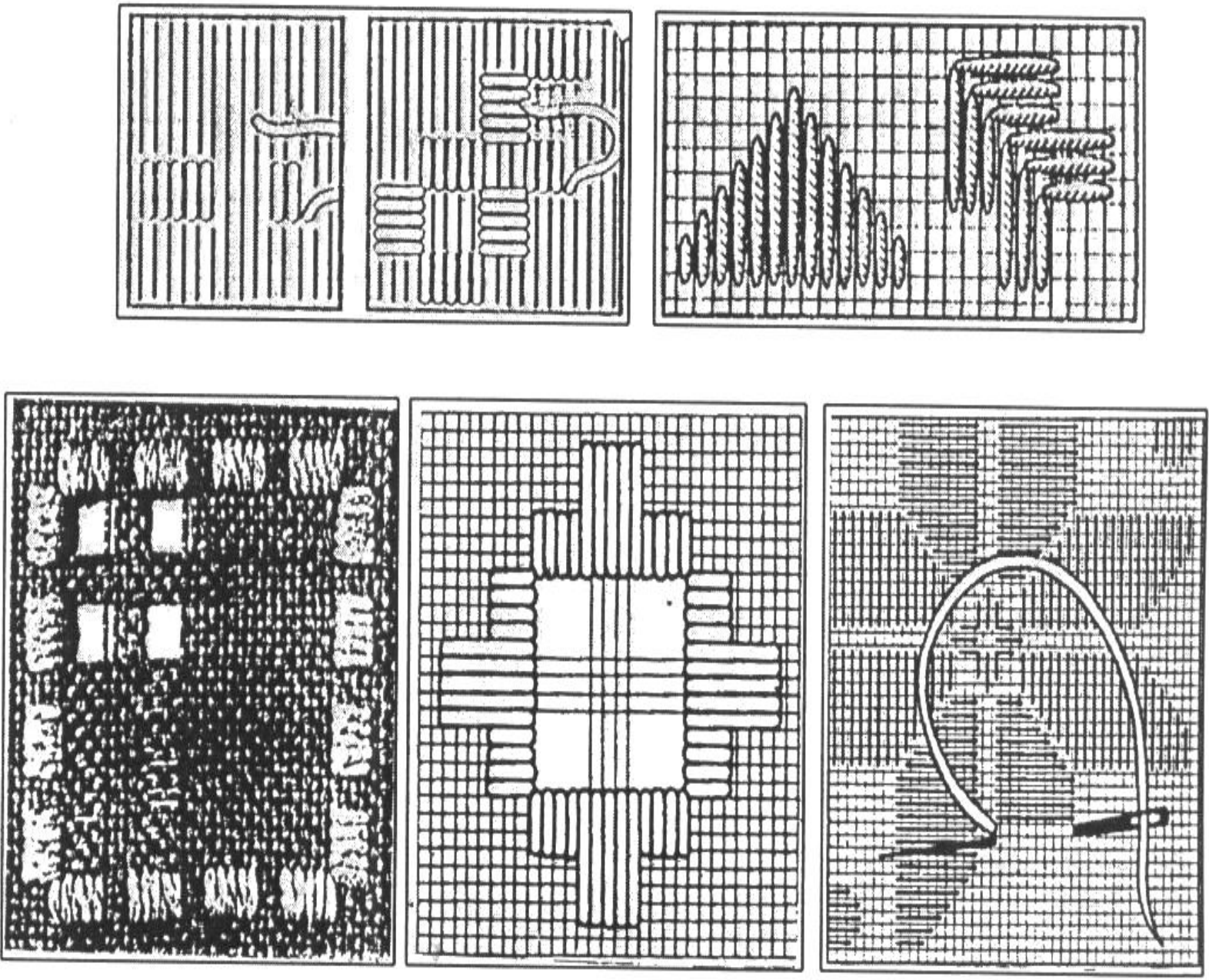

شكل ( ا أشكال مختلفة لغرزة الساتان 


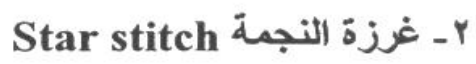

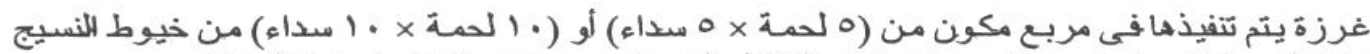

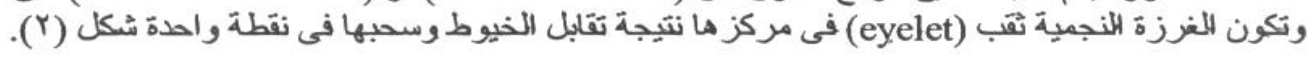

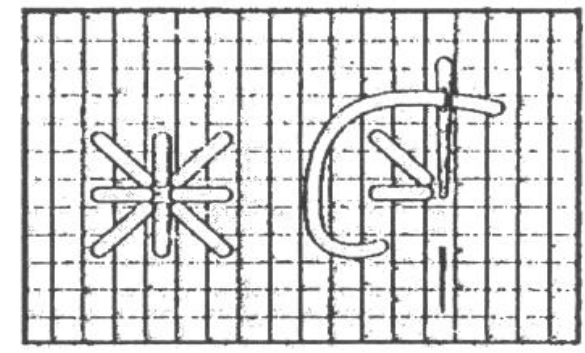

شُكل (r) غرزة النجمة (Star stitch)

Maderia stitch M- غرزة ماديرا

غرزة تمانل غرزة النجمة ولكن تكثر أشعتها الخارجية من المركز شكل (r).

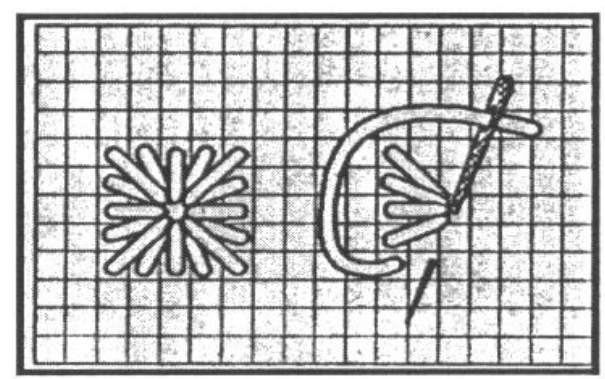

شكل (T) غرزة ماديرا (Maderia stitch)

ـ ـ الغرزة الربع مالطية One quarter maltese cross

غرزة أساسية فى نماذج التطريز الثقيل (Hardanger) ويمكن استخدامها بمفردها أو مع عناصر أخرى ويتم

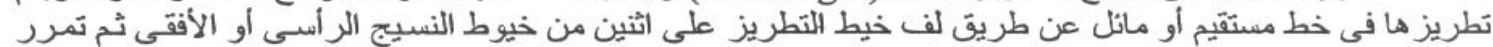

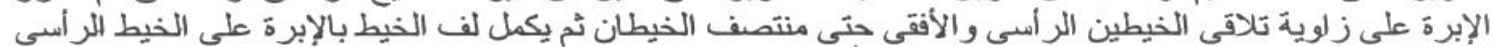

أو الأفقى شكل (ع) (ع ).

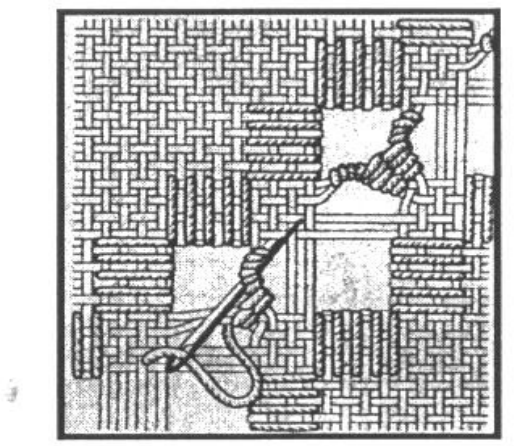

شنكل (ع) الغرزة التربع المالطية (quarter Maltese) 
Maltese cross ـ الاغرزة المالطية الكاملة

هى غرزة تشبه الغرزة المربع ملطية فى طريقة تتفيذها ولكن يتم تتفيذها فى الأربعة أركان شكل (0).

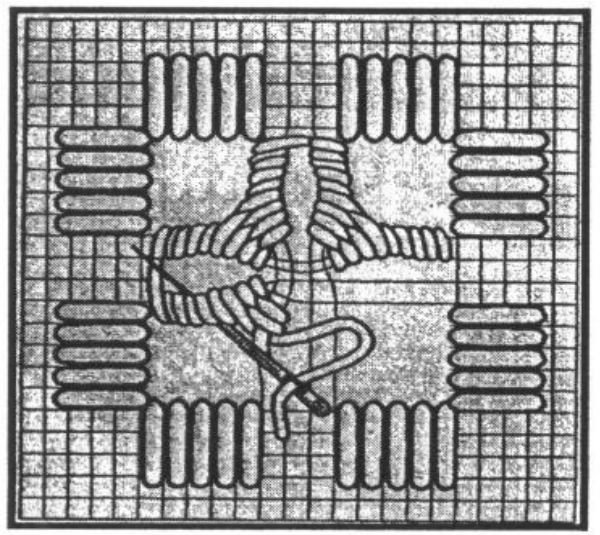

شكل (0) الغرزة المالطية الكاملة (Maltese cross)

Simple back stitch الغرزة الخلفية البسيطة

غرزة يتم تنفيذها من اليمين إلى اليسار حيث تدخل الإبرة على يمين النسيج على بعد ع فتلة ويتم إخراجها من

اليسار على بعد ع فتلة وتشبه غرزة النباته (شكل 17).

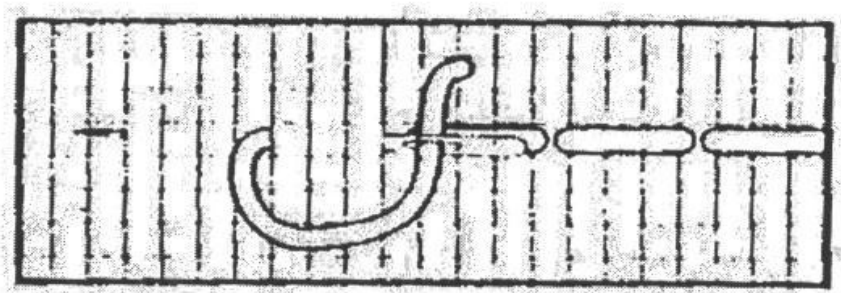

شكل (T) الغرزة الخلفية البسيطة (Simple back stitch)

Yـ الغززة الخلفية المزدوجة: Cable stitch (Double back stitch)

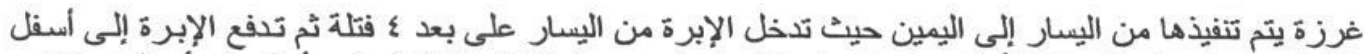
فى اتجاه مائل تحت منتصف الغرزة الأولى ويتم إخر اج الإبرة على بعد ع فتلة ثم الانتقال إلى أعلى ثلى ثم أسفل و هكذا...

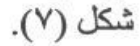

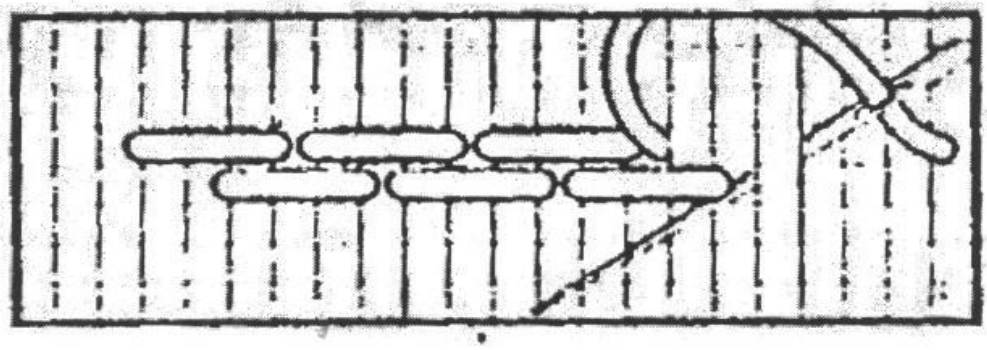

شكل (V) اللغرزة الخلفية المزدوجة (Cable stitch) 


\section{1ـ الغرزة الخلفية المايلة Diagonal Cable Stitch}

غرزة يتم تتفيذها عن طريق إدخال الإبرة تحت خيطين أو أربعة من الخيوط الأفقية للنسيج وتحت خيطين أو

أربعة من خيوط النسيج الراسى شكل شريث (^)
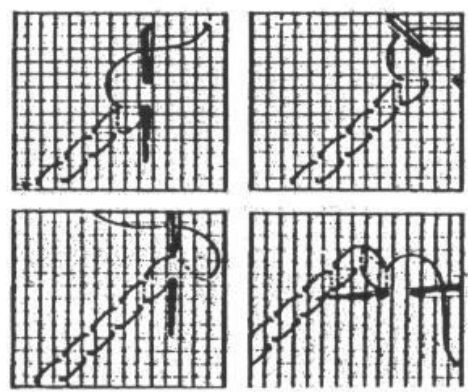

شكل (^) شكل الغرزة الخلفية المايلة (Diagonal cable stitch)

9ـ نسج الحواجز Woven bars

تنفذ عن طريق إمرار الإبرة فوق اثثين من خيوط الشبكة الداخلية سواء الرأسية أو الأفقية وتحت أثنين من

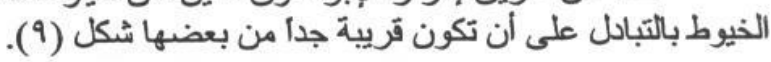

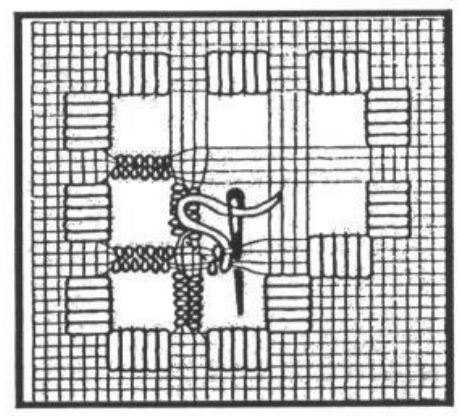

شكل (9) نسيج الحواجز (Woven bars)

• إ- نسج الحواجز مع غرزة البيكو: Woven bars with picots يتم تنفيذ هذه الغرزة بنفس طريقة تطريز الحواجز ولكن مع لف لف الخيط على الإبرة مرتين أو ثلاثة فى منتصف

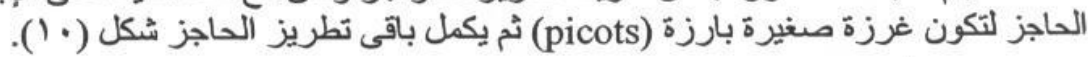

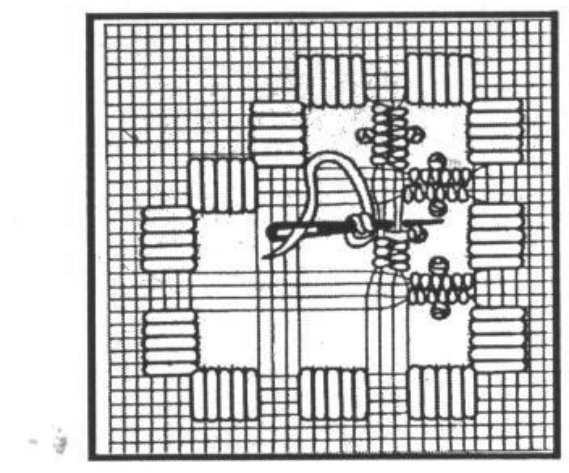

شكل (• (1) نسيج الحواجز مع غرزة البيكو 


\section{1ـ الغرزة الخلفية الماتلة Diagonal Cable Stitch}

غرزة يتم تنفيذها عن طريق إدخال الإبرة تحت خيطين أو أربعة من الخيوط الأفقية للنسيج وتحت خيطين أو

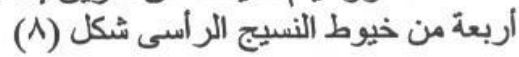
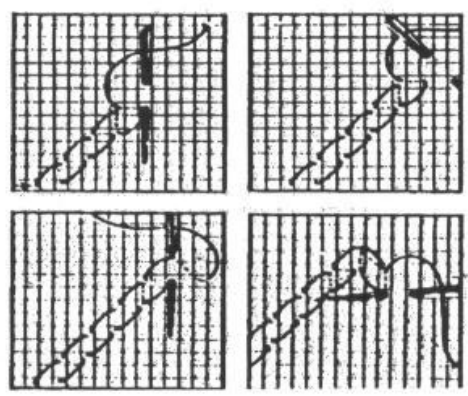

شكل (^) شكل الغرزة الخلفية المائلة (Diagonal cable stitch)

9 - نسج الحواجز Woven bars

تنفذ عن طريق إمرار الإبرة فوق اثنين من خيوط الشبكة الداخلية سواء الرأسية أو الأقية وتحت أثنين من

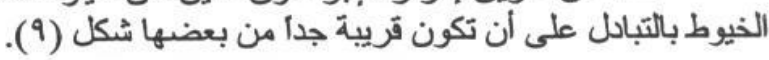

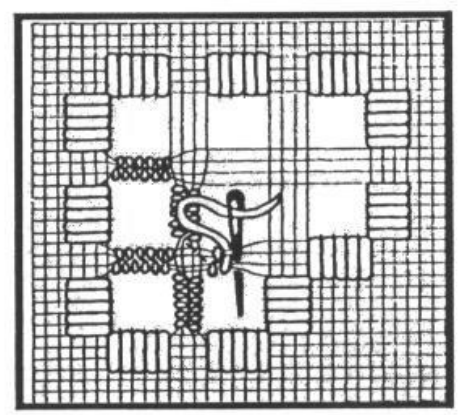

شكل (9) نسيج الحواجز (Woven bars)

م اـ نسج الحواجز مع غرزة البيكو: Woven bars with picots يتم تنفيذ هذه الغرزة بنفس طريقة تطريز الحواجز ولكن مع لف تلف الخيط على الإبرة مرتين أو ثلاثثة فى منتصف

الحاجز لتكون غرزة صغيرة بارزة (picots) ثم يكمل باقى تطريز الحاجز شكل (•) (1).

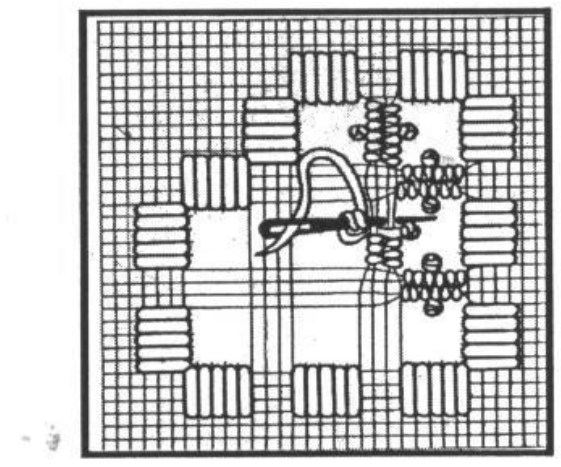

شكل (• (1) نسيج الحواجز مع غرزة البيكو 
ا 1 ـ طريقة الحبل أو لف الحواجز corded bars (over cast bars) تتفذ عن طريق لف الخيط فوق أربعة خيوط أو أثنين من خيوط النسيج الر أسى أو الأفقى للشبكة الداخلية من

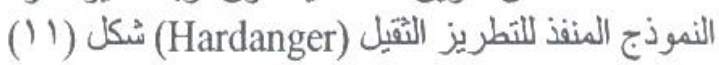
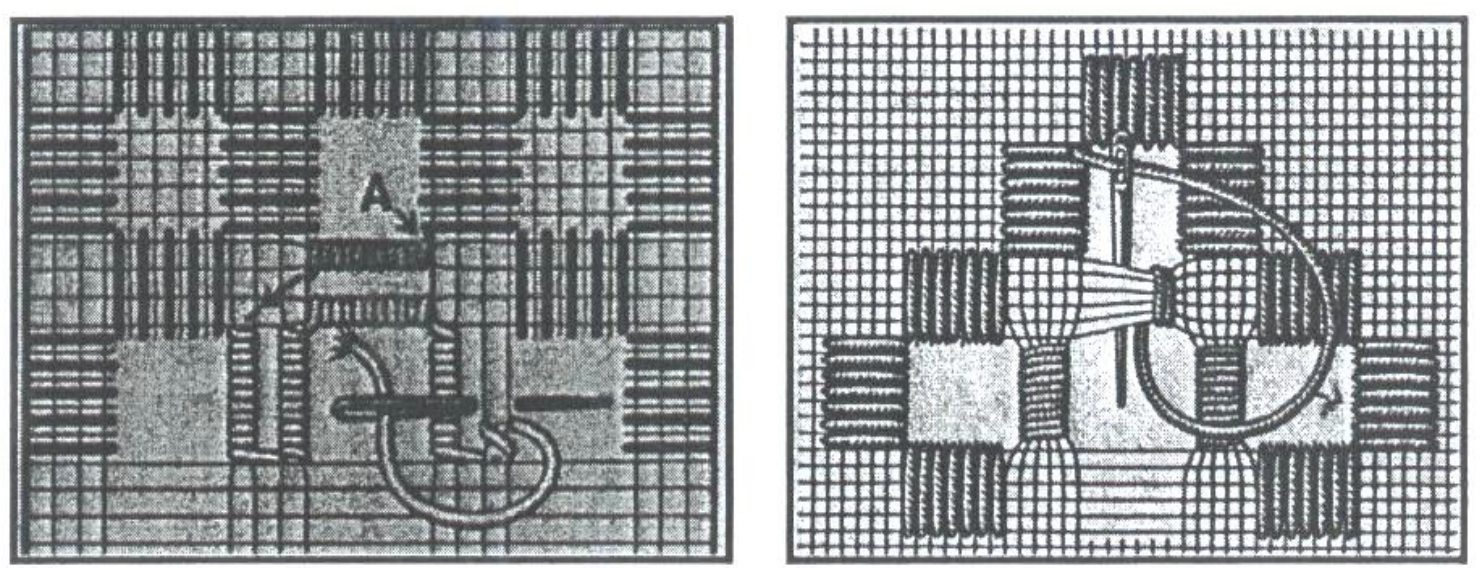

$$
\text { شكل (l' (') طريقة الحبل أو لف الحواجز }
$$

Loop stitch filler إ غرزة العروة

غرزة يتم تنفيذها أثناء نسج الحواجز الداخلية للشبكة وتكون فى منتصف الحواجز من أعلى إلى أسفل أو يتم

تنفيذها على الجوانب شكل (IY) (IY).
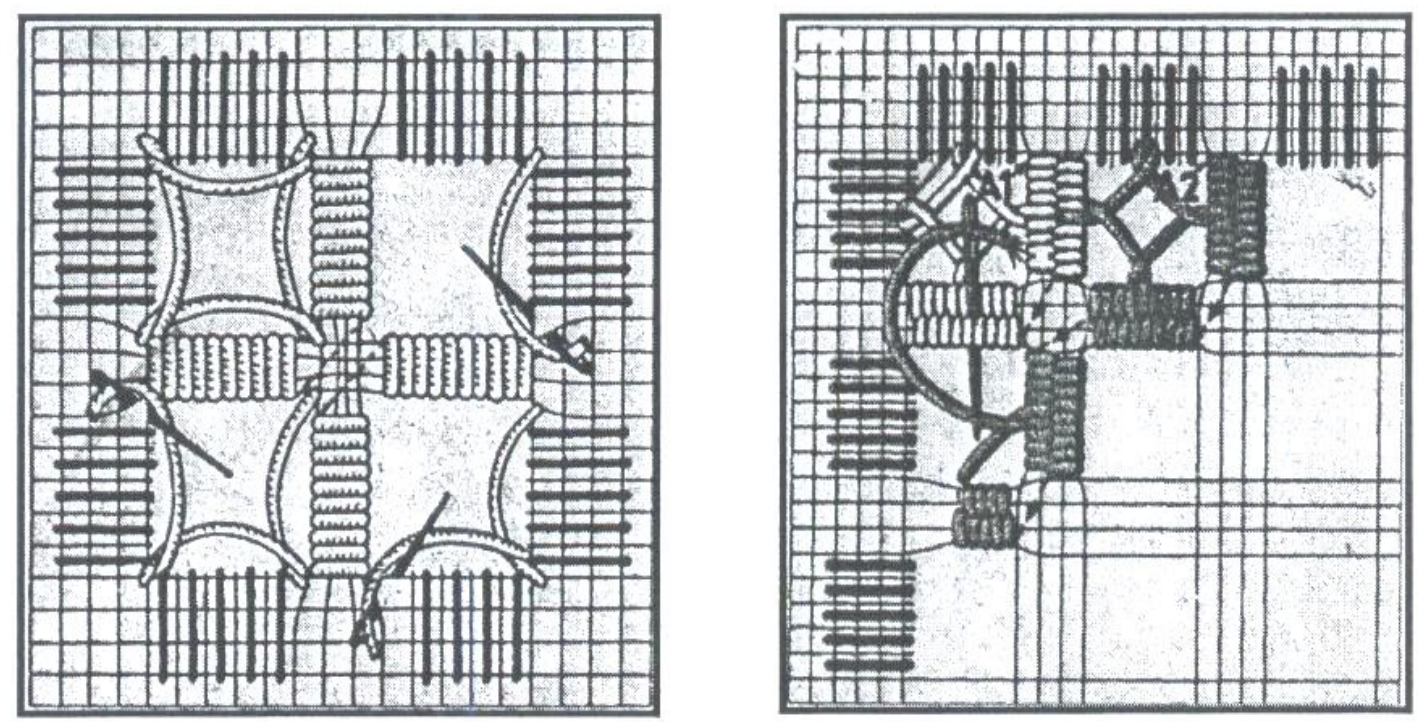

شكل (rا (Ioop stitch filler) غرزة العروة 
Training of وهذه العينة يقمن بتدريب فئات أخري مستهدفة Trainer

\section{ب- محتوي الوحدات التعليمية :}

تم الاستعانة ببعض المراجع العملية والمحلات الأجنبية وشبكة المعلومات لصياغة البرنامج التدريي في صورة حلقات تعليمية

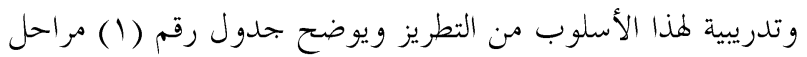

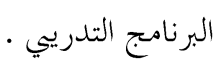

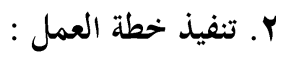

$$
\text { وتشتمل علي المراحل التالية : }
$$

أ- زيارات ما قبل تنفيذ خطة العمل للاتفاق علي الأماكن

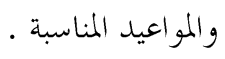

ب- تحديد الطرق والمعينات الإرشادية اللازمة لتنفيذ البرنامج · مواميد

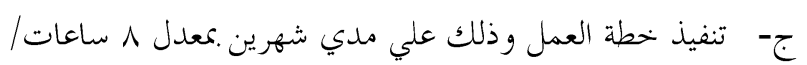

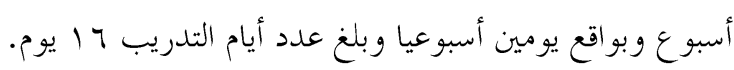

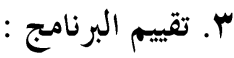

حيث تم استخدام استبيان ( قبلي- بعدي ) لتحديد مدي التغير

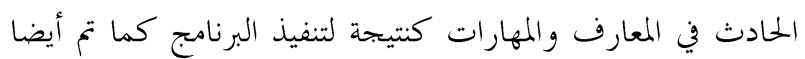
تحديد مدي صدق المقياس من خلال عرضه علي بمموعة من المتخصصين لإبداء الرأي وتم تعديل وحذف وإضافة بعض العبارات في صورةا النهائية والتي اشتملت علي عدة محاور تمثلت في :

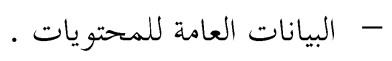

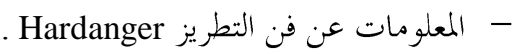

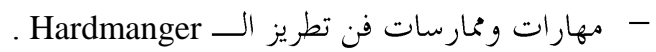
رابعا : تحليل البيانات والمعالجة الإحصائية بعل إجراء التقييم من قبل المحكمين المتخصصين بإعطاء درجة مــن

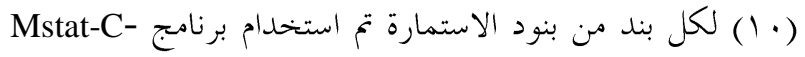

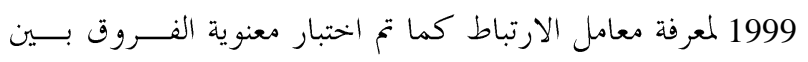

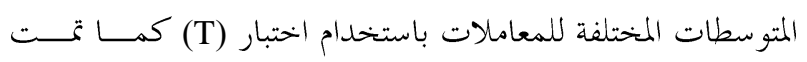

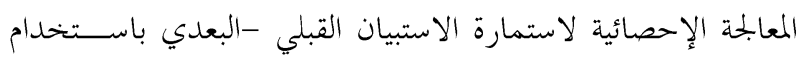

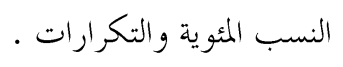

\section{ه.تحكيم النماذج النسيجية المطرزة ..}

تم إعداد النماذج النسجية بأحجام تتناسب مع التصميم

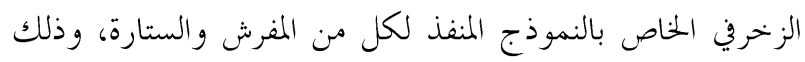
باستخدام الخيوط والأقمشة موضع الدراسة وذلك لإجراء التحكيم

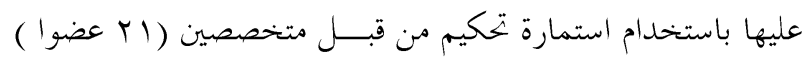

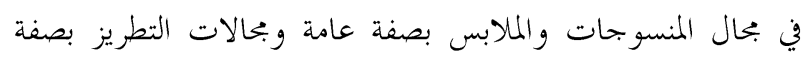
خاصة وهم كالتالي : • أعضاء هيئة التدريس بقسم الاقتصاد المتزلي كلية الزراعة-جامعة

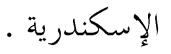
• أعضاء هيئة التدريس بكلية التربية النوعية- جامعة الإسكندرية.

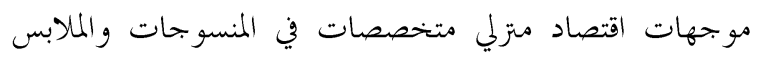

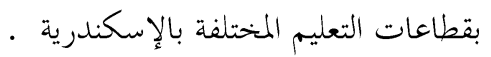

حيث اشتملت استمارة التحكيم للنماذج المطرز علي البنود التالية :

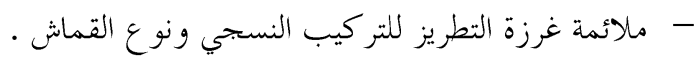

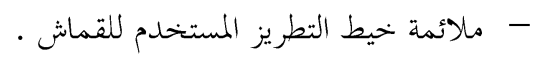

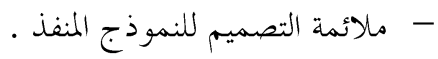

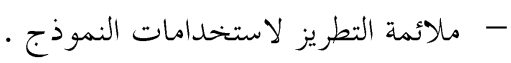

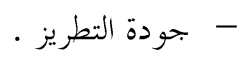
- مدي تميز و انفر اد التطريز.

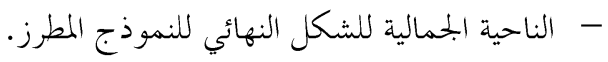
وقد تم تحكيم بنود الاستمارة للتأكد من استيفائها لهدف الدراسة، وتم حذف وتعديل وإضافة بعض البنود، وقد تم التقييم

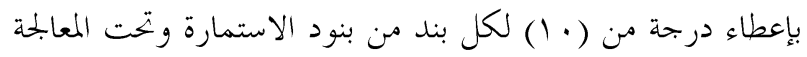
الإحصائية باستخدام برنامج Mstat-C-1999 . ثالثا : تخطيط وتنفيذ البرنامج التدريبي :

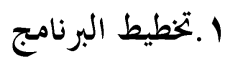
أ- تحديد المستهدفين من التدريب : تم اختيار عدد (·• (1) من المدربات العاملات في بحال تدريب الخريجات بمناطق مختلفة من الإسكندرية. 
جدول رقم 1. البرنامج التدريبي المقترح

الو سائل التعليمية والأدوات

أقمشة خاصة بطريقة التطريز.

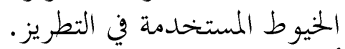
أدوات التطريز الثقيل. منتجات عينية للغرز.

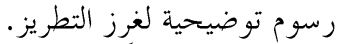

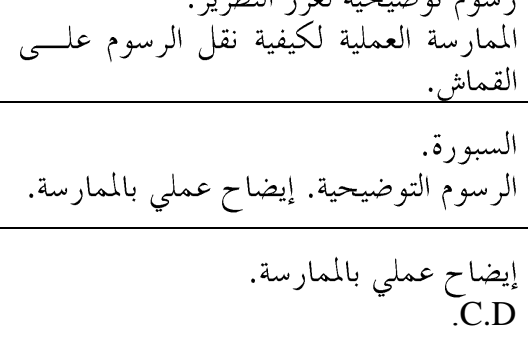

الختوى مقدمة عن فن التطريز الثقيل

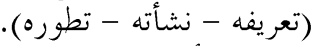
التعر ف على الأقمشة والخيوط والته والأدوات المستخدمة في فن التطريز الثقيل. التعرف على الغرزة الأساسية لفن التطريز الثقيل.

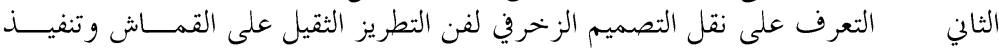
وحدة زخرفية. الأول الأسبو ع الثالث التعرف على مختصرات ورموز الباترونات الخاصة بالتصميم الزخرفي للتطريسـز التعرف على قص الخيوط وتكوين الشبكة التي سوف يتم التطريز عليها.

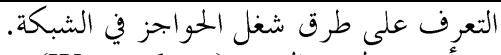

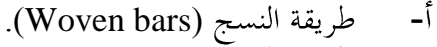

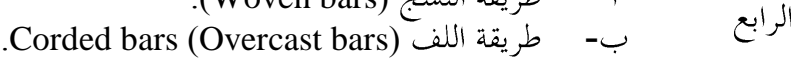
ج- بر طبقة النسج مع غرزة البيكو (Woven bars with picot).

\begin{tabular}{|c|c|c|}
\hline 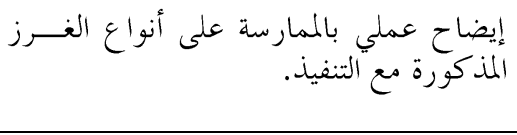 & 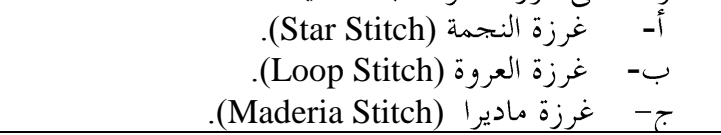 & الخامس \\
\hline إيضاح عملي بالممارسة مع التنفيذ مع عرض & 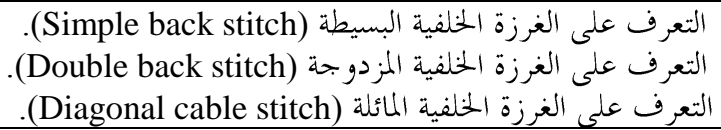 & السادس \\
\hline عمل معرض للمنتجات النسيجية المطرزة. & التعرف على على ربع الغرزة المالطية(Q) الغراملة (Maltese). & 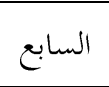 \\
\hline & إستكمال منتج مطرز في صورته النهائية. & الثامن \\
\hline
\end{tabular}

الجمالية للشكل النهائي عند مستوي معنوية (1 (, •) ، (0., •) علي التوالي ويوضح جدول رقــم (r) هذه النتائج · كما أظهرت نتائج اختبار (t) بين متوسطات بنود تحكيم مظهرية النماذج المطرزة وبين نوع الأقمشة (جدول رقمب) أن القماش السادة الممتد من الابتحيــن ب/ ب (قطن . . 1\% ) قد حصل علي اعلي درجات التقييم لجميع بنود مظهرية التطريز، واختلف معه القماش السادة الممتد من السداء ب/س (قطن . . | \%)فقط في ملائمة غرزة التطريز للتركيب النسجي ونوع القماش. وتؤ كد) Sylvia Muir 2004 ) أن القماش الشائع استخدامه حاليا في تطريز الــ Hardanger من النسيج القطين ذو التركيب النسجي السادة وهو يجتوي علي ب بخيط لكل بوصة، وهو الذي يعطي نتائج جيدة للتطريز ويناسبه، وقل ظهرت حديثا بعض الأقمشة الاخري ذات التركيب النسجي السادة وتلاءم أيضا هذا النوع من التطريز . ويوضح جدول رقم (ع) تأثير نوع الخيط علي بنود تحكيم مظهرية

\section{النتائج والمناقشة}

\section{أولا : نتائج تحكيم وتقييم نماذج للمفروشات:}

: Table Cloth المفرش

أظهرت نتائج تحليل التباين بين بنود تحكيم مظهرية النماذج المطرزة وبين كل من نوع الأقمشة ونوع الخيوط وتداخل الخيوط والأقمشة معا أن تأثير القماش كان معنويا لكل من ملائمة غرزة التطريز للتركيب النسيجي ونوع القماش وجودة التطريز، والناحية الجمالية للشكل النهائي وذلك عند مستوي معنوية (1 +., ·). في حين كان تأثير نوع الخيوط معنويا بالنسبة لكل من ملائمة خيط التطريز المستخدم للقماث وجودة التطريز والناحية الجمالية للشكل النهائى عند مستوي (1., (·) ، (0., ·.) وبالنسبة لتأثير تداخل اللخيوط مع الأقمشة علي بنود تحكيم النماذج النسيجية المطرزة فقد اتضح أن هناك علاقة معنوية كبيرة لكل من جودة التطريز والناحية 
جدول رقم r. تحليل التباين لبنود تحكيم مظهرية النماذج النسيجية المطرزة

\begin{tabular}{|c|c|c|c|c|c|c|c|c|}
\hline \multicolumn{7}{|c|}{ النباين لبنود تحكيم مظهرية النماذج النسيجية المطرزة } & \multirow[b]{2}{*}{ درجات الحرية } & \multirow[b]{2}{*}{ مصدر الإختلاف } \\
\hline اللشكل النهائي & التطريز لــــــز & التطريز & 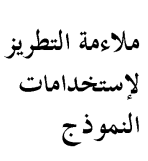 & 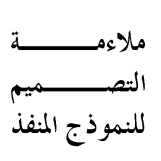 & 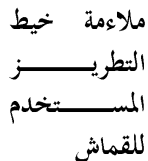 & 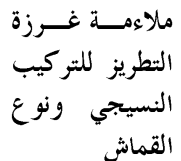 & & \\
\hline$*_{T}, V T V$ & ${ }^{N} . S, \ldots o$ & $\underset{*\rceil, \wedge 10}{* *}$ & $\mathrm{~N}_{Y}, 0 \leqslant 0$ & N.S $_{Y, Y_{Y}}$ & 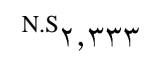 & ****T, Ir, Y.Y & r & بين الأقمشة \\
\hline${ }^{*} r, 1.1$ & N.S., , rI & 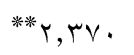 & ${ }^{N} . S_{Y, q Y Y}$ & N.S,, $1 \leqslant 9$ & **** $\mid \leq, 109$ & N.S , , Y. Y & r & بين الخيوط \\
\hline * & N.S., & ${ }^{* * *} \leftarrow$, r 99 & N.S.,,$q \cdot r$ & N.S., 990 & N.S.,$r \leqslant q$ & N.S , ,007 & $\varepsilon$ & تداخل الخيوط مع القماث \\
\hline$\cdot, 7 \times 1$ & $\cdot, \cdot, Y 4$ & $\cdot, \infty$ & 1,109 & $\cdot, 9 r v$ & $\cdot, 911$ & $\cdot, v \leq \varepsilon$ & $\begin{array}{r}11 . \\
., .0 \text { s } \\
. ., \\
. .,\end{array}$ & 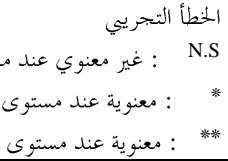 \\
\hline
\end{tabular}

جدول رقم r. متوسطات تأثير نوع القماش على بنود تحكيم مظهرية التطريز للنماذج النسيجية:

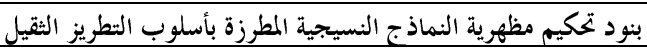

\begin{tabular}{|c|c|c|c|c|c|c|c|}
\hline \multicolumn{7}{|c|}{ بنود تحكيم مظهرية النماذج النسيجية المطرزة بأسلوب التطريز الثقل } & \multirow{3}{*}{ وع القماش } \\
\hline الناحية الجمالية & مــــى تيـــز & جودة التطريز & ملاءمة التطريز & ملاءمة التصميم & 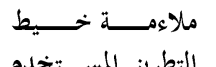 & 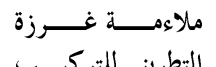 & \\
\hline للشكل النهائي & التطريز & & اللاستخدامات & للنموذج المنفذ & للقماش المسرستخدم & 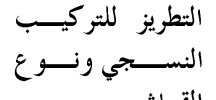 & \\
\hline
\end{tabular}
(A) $9, \Sigma 9 \mathrm{r}$
(A) $9,97 \wedge$
(A) $9, \vee \vee \varepsilon$
(A) $q, r \cdot r$
(A) 9,194
(A) 9,109
(A) $9,77 \mathrm{Y}$

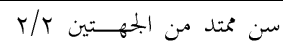
(A) 9,901
(A) $9, १ \wedge \varepsilon$
(A) 9,701
(A) $9, \uparrow \wedge$
(A) $9, \sum \vee 4$
(A) $9, r \cdot r$
(B) $9, \cdot r r$

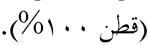
(B) $\wedge, r<9$
(A) 9,974
(B) $\wedge, 19$.
(A) $9, \ldots$
(A) 9,111
(A) $\wedge, q$,
(C) $7,9,1$

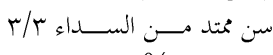
غير معنوي
$\cdot, r>19$
غير معنوي
غير معنوي
غير معنوي
$\cdot, r \cdot \leqslant 7$

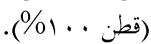

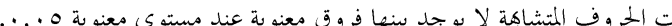

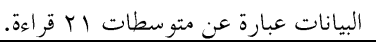

درجات التقييم مع كل من خيط المالونيه وخيط الكتون بارليه وحصولم علي درجات اقل مع خيط السو لافابل .

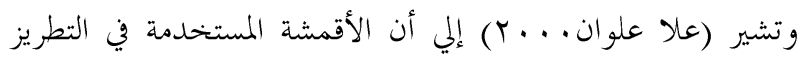

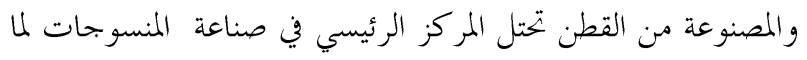

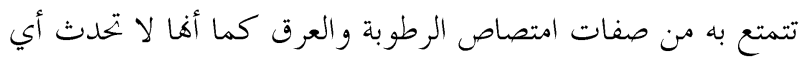

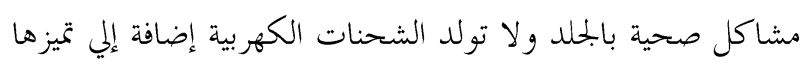

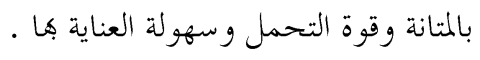

\section{Curtain ب الستارة}

من نتائج تحليل التباين بين بنود تحكيم مظهرية النماذج المطرزة

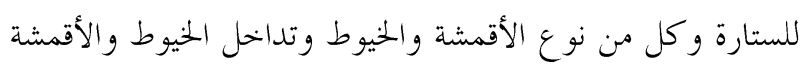

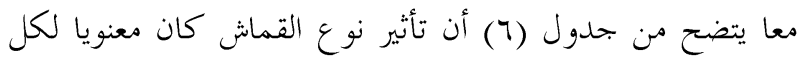

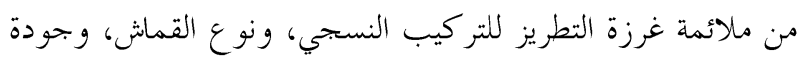

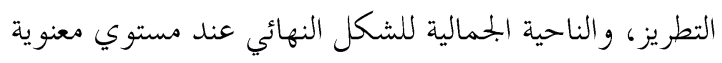

النماذج حيث أن اعلي درجات التقييم كانت لخيط المالونيه

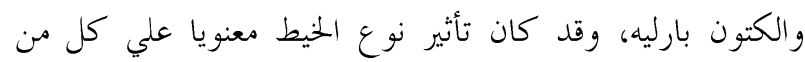
ملائمة خيط التطريز المستخدم للقماش وجودة التطريز والناحية الجمالية للشكل النهائي عند مستوي معنوية (0, م. · ) .

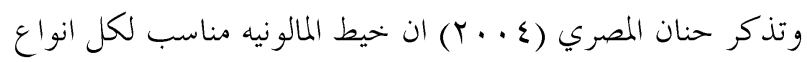

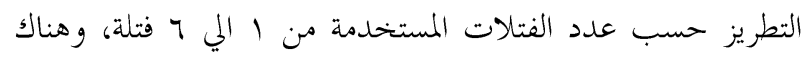
بحموعة كبيرة من الالوان ذات صباغة ثابتة ويتحمل الغسيل المتكرر

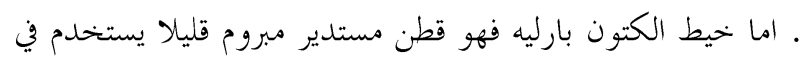
التطريز . التمان وتشير نتائج اختبار (t) أيضا (جدول رقم ه ) إلي ان درجات التقييم

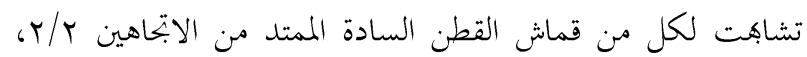

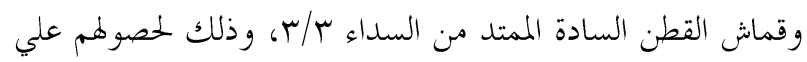




\section{جدول رقم ع. متوسطات تأثير نوع الحيط على بنود تحكيم مظهرية النطريز للنماذج النسيجية}

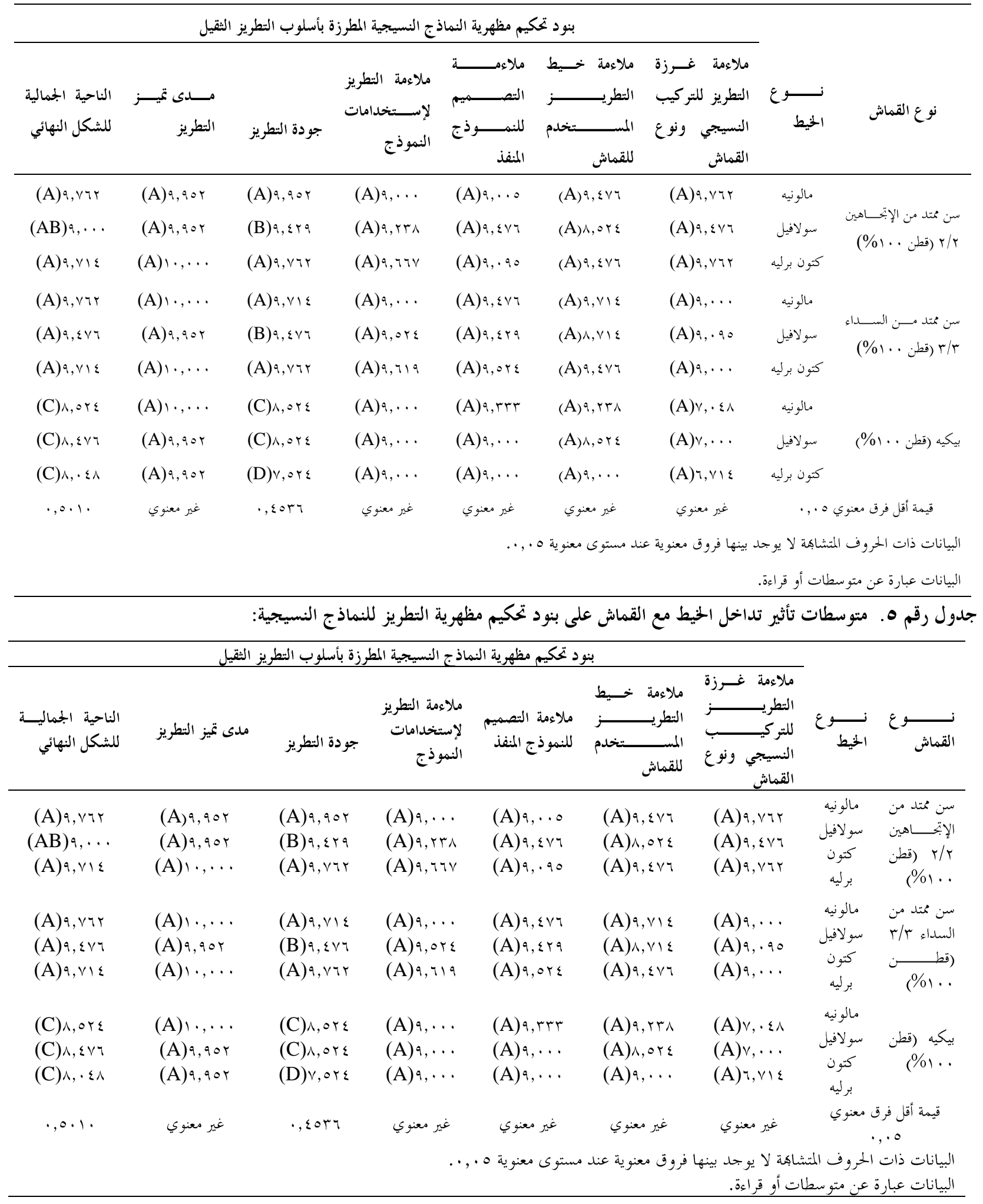


جدول رقم 7.

\begin{tabular}{|c|c|c|c|c|c|c|c|c|}
\hline \multicolumn{7}{|c|}{ التباين لبنود تحكيم مظهرية النماذج النسيجية المطرزة بأسلوب التطريز الثقيل } & \multirow[b]{2}{*}{ درجات } & \multirow[b]{2}{*}{ تصدر الإختلاف } \\
\hline للشكل النهائي الجمالية & ملدى تميز & النطريز & لالإستخدامات التطريز & للنموذ التصميم & لماءمة خيط & للملاءمة غرزة التطريز & & \\
\hline$*_{r}^{*}, V \neg V$ & $N^{N . S},, r V$ & $* * \varepsilon \vee, \wedge 10$ & N.S $S_{Y, O}$ o & N.S $_{r, 111}$ & N.S $_{r, O}$ Or & $* * \mid r o, 111$ & r & بين الأقششة \\
\hline$* r, 1 \cdot 1$ & N.S,,$\ldots \circ$ & $*^{* *} Y, 0 \leq 0$ & N.S $_{r, q Y Y}$ & N.S.,r.Y & $* *\left|r, \sum \wedge\right|$ & N.S., & r & بين الخيوط \\
\hline$*_{1, \Lambda T 1}$ & N.S,,$\ldots$ & ${ }^{* * *} r$, oor & N.S,,$q \cdot r$ & N.S , ,97. & N.S & N.S , ,007 & $\varepsilon$ & تلداخل الحيوط مع \\
\hline$\cdot, \gamma \cdot \circ$ & $\cdot, \cdot r$ & $\cdot$, OVt & I,rYT & $\cdot, 974$ & $\cdot, 91 \wedge$ & $\cdot, \wedge r \varepsilon$ & مستوى ه. . . 11. & 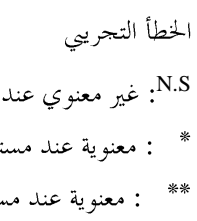 \\
\hline
\end{tabular}

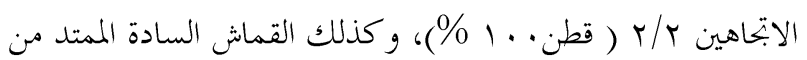
السداء ب/r ( قطن . . 1 \% \%) مع كل من خيط المالونية والكتون برليه وتشير النتائج بوجه عام إلي أن تأثير تداخل الخيط مع من القماش كان معنويا بالنسبة لجودة التطريز والناحية الجمالية للشكل النهائي

$$
\begin{aligned}
& \text { عند مستوي معنويــــــة (0., · ) . } \\
& \text { ثانيا: نتائج البرنامج التدريبي التطبيقي }
\end{aligned}
$$

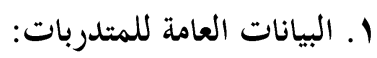

أظهرت نتائج الدراسة أن عدد (V) من المبحوثات حاصلات

علي بكالوريوس زراعة مقابل ( r ) بكالوريوس علوم قطن . كما أن (V) منهن يعملن مدربات في مراكز صناعات صغيرة

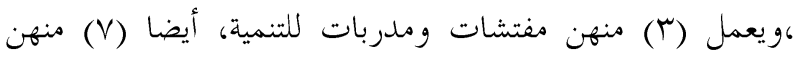

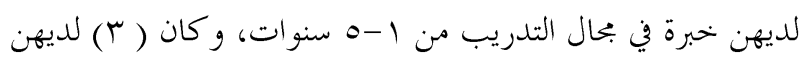

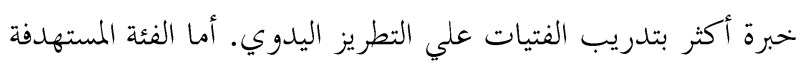

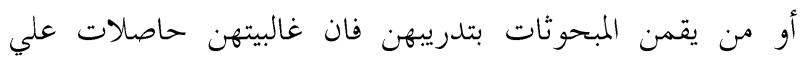
مؤهلات متوسطة أو أميات.

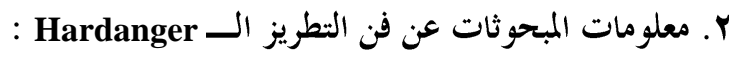
يوضح جدول رقم (·ل) أن هناك ارتفاعا في معلومات

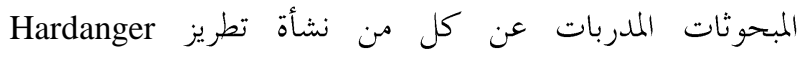
واستخداماته وكيفية اختيار التركيب النسجي الملائم له ونقل
(1 (, ·)، في حين كان تأثير نوع الخيط علي كل من ملائمة خيط

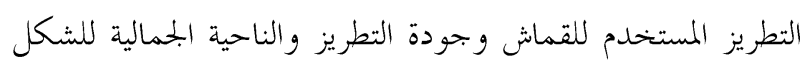

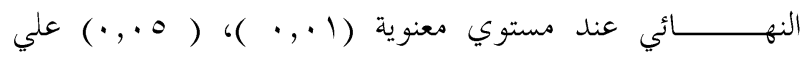
التوالي، كذلك فان تأثير تداخل الخيوط مع الأقمشة كان شديد

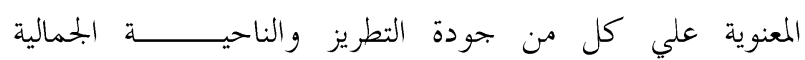

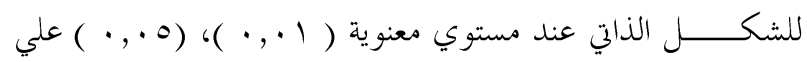
التوالي كما أظهرت نتائج اختبار (t) بين متوسطات بنود تحكيم

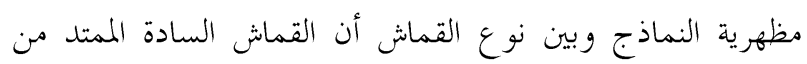

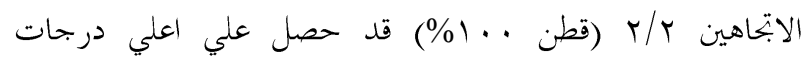

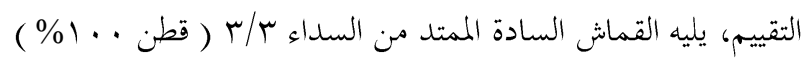

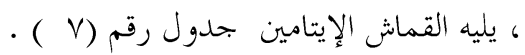

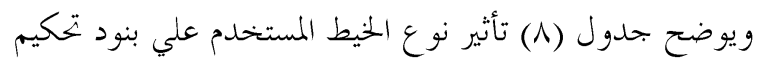
مظهرية النماذج المطرزة حيث حصل خيط المالونية علي اعلي درجات التقييم وكذلك خيط الكتون بارليه حيث كان تأثير الخيط عليط الميطي معنويا علي كل من ملائمة خيط التطريز المستخدم للقماش، كذلك ونك جودة التطريز والناحية الجمالية عند مستوي معنوية ( ه. ., •).

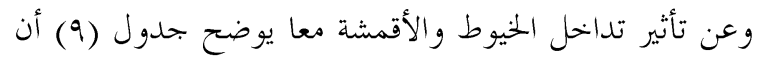

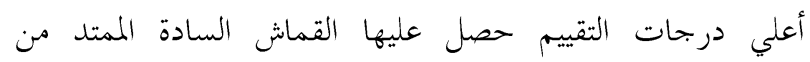


جدول رقم V. متوسطات تأثير نوع القماش على بنود تحكيم مظهرية النماذج المطرزة:

بنود تحكيم مظهرية النماذج النسيجية المطرزة باسلوب التطريز الثقيل

\begin{tabular}{|c|c|c|c|c|c|c|c|}
\hline النائية النيائي للشكل & 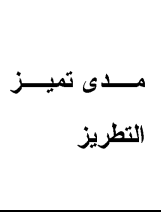 & جودة التطريز & 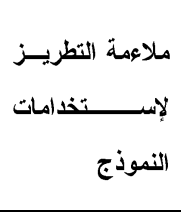 & للنموذج المنفذ التصميم & ملاءعمة خيط التطريز & 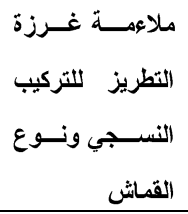 & نوع القماش \\
\hline (A) q, \&१५ & (A) १,१८ & (A) $9, \mathrm{~V}, \varepsilon$ & (A) $q, r \cdot r$ & (A) $9,19$. & (A) $9,1 \leqslant r$ & (A) $৭, 77 \mathrm{~V}$ & 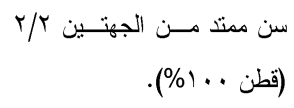 \\
\hline (A) 9,701 & (A) $9,0 \mathrm{r}$ & (A) 9,701 & (A) $9, r \wedge 1$ & $(A)^{9, \varepsilon}$. & (A) $q, r \cdot r$ & (B) $q, \cdot r r$ & 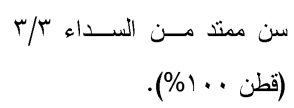 \\
\hline (B) $\wedge, r \leq q$ & (A) $1,, \ldots$ & (B) ^, $1 \mathrm{vo}$ & (A) $9, \ldots$ & $(A)^{9}, 111$ & (A) $1,9.0$ & (C) $\uparrow, \wedge \vee r$ & بيكيه (قطن . . 1\%). \\
\hline$\cdot, r 970$ & غير معنوي & , YTYו & غير معنوي & غير معنوي & غير معنوي & $\cdot, r r \cdot T$ & قيمة أقل فرق معنوي ه,.. \\
\hline
\end{tabular}
البيانات ذات الحروف المتشاهية لا يوجد بينها فروق معنوية عند مستوى معنوية ه. ., .. البيانات عبارة عن متوسطات إب قر اءة. جدول رقم ^. متوسطات تأثير نوع الحيط على بنود تحكيم مظهرية النماذج النسيجية بنود تحكيم مظهرية النماذج النسجية المطرزة بأسلوب التطريز الثقيل

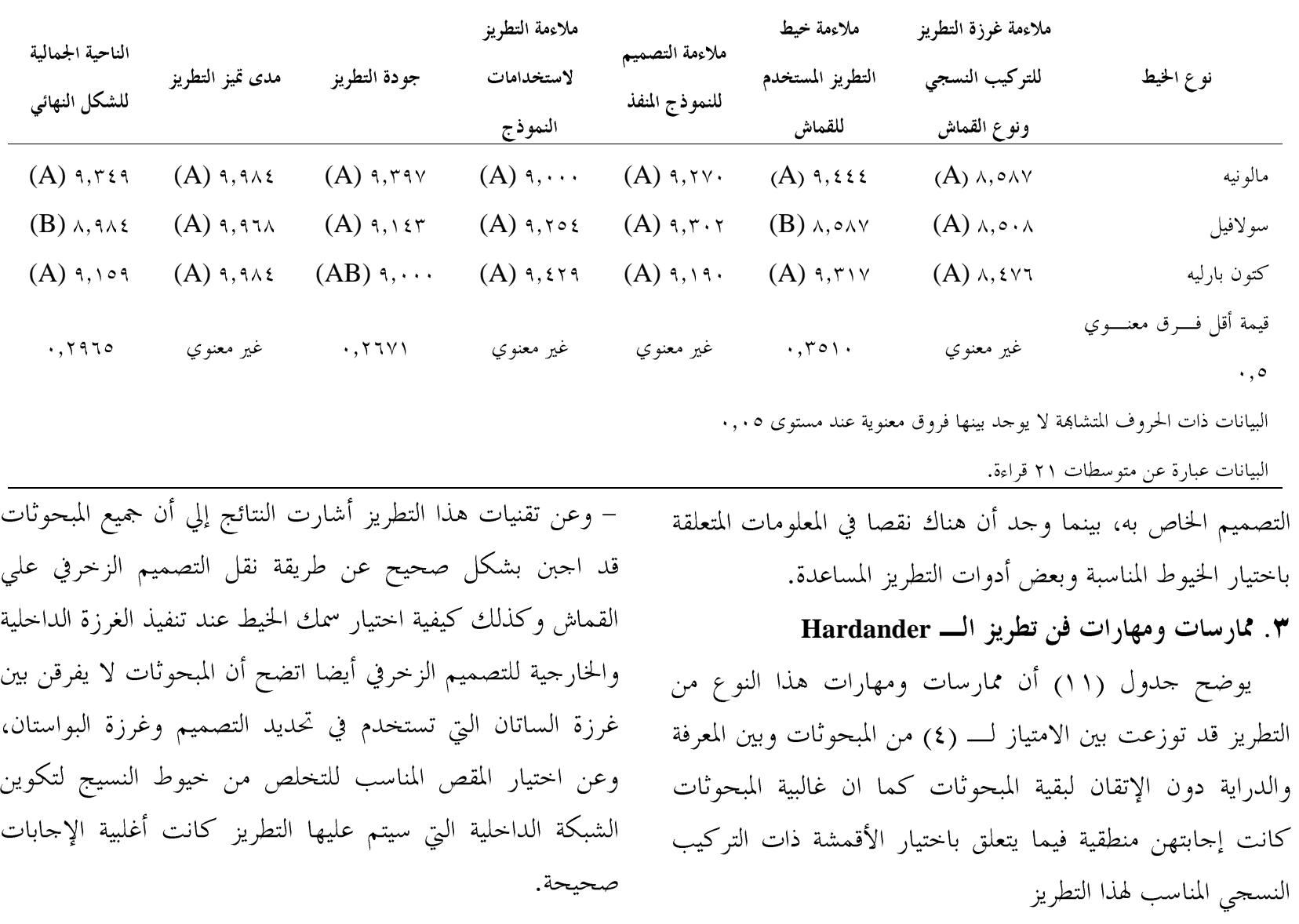




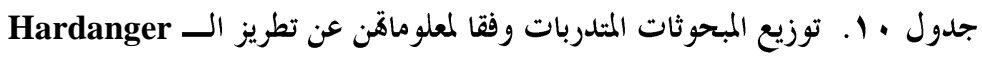

\begin{tabular}{|c|c|c|c|}
\hline 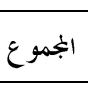 & عدد الإجابات & ع الصديحة الإبات & 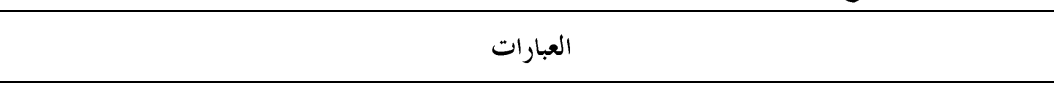 \\
\hline 1. & - & 1. & فن التطريز الثقيل (إإيطلي - فرنسي - نرويجي) \\
\hline 1. & r & $\wedge$ & يستخدم فن التطريز الثقيل في تطريز (الملابس - المفروشات - الملابس والمفروشات) \\
\hline 1. & - & 1. & النسيج) التصميم الزخرفي للتطريز الثقيل على القماش عن طريق (الكربون - الرسوم المشفوفة - التخريم - العد على \\
\hline 1. & r & v & الخيوط المستخدمة في التطريز الثقيل من (خيوط حريرية - خيوط قطنية - خيوط صوفية - خيوط معدنية) \\
\hline 1. & - & 1. & التر كيب النسجي الملائم للتطريز الثقيل (تركيب نسجي سادة - تركيب نسجي أطلس - تركيب نسجي مبردي) \\
\hline 1. & - & 1. & طرف مدبب - منتحص منير) الميوط لتكوين الشبكة للتطريز الثقيل (مقص صغير ذو طرف عريض - مقص صـير ذو \\
\hline 1. & $\varepsilon$ & 7 & يستخدم الأطار في التطريز الثقيل لآنه يعمل على (شد النسيج - سهولة العمل - تثبيت خيوط السداء واللحمة) \\
\hline 1. & $\varepsilon$ & 7 & 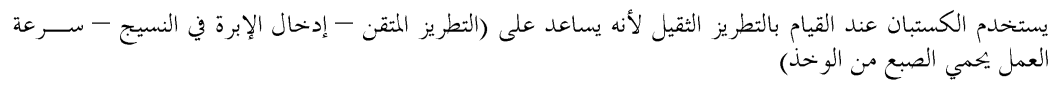 \\
\hline 1. & - & 1. & 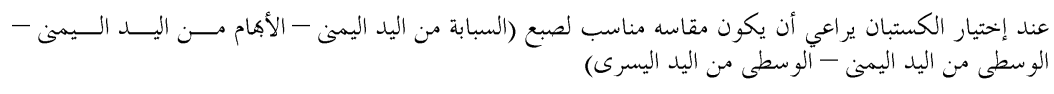 \\
\hline
\end{tabular}

جدول 11. توزيع المبحوثات المتدربات تبعا لممارسات ومهارات تطريز الــ Hardanger عدد

المجموع

أوافق أوافق لحد ما ل لا أوافق

العبار ات

\begin{tabular}{|c|c|c|c|c|}
\hline 1. & 7 & - & $\varepsilon$ & أجيد أو أتقن فن التطريز اليدوي. \\
\hline 1 . & 1 & - & 9 & أقوم باستخدام الأقمشة ذات التركيب النسجى السادة في التطريز الثقيل . \\
\hline 1 . & 9 & - & 1 & أقوم باستخدام الأقمشة ذات التر كيب النسجى الأطلسى في التطريز الثقيل \\
\hline 1. & 9 & - & 1 & أقوم باستخدام الأقمشة ذات التركيب النسجى المبردي في التطريز الثقيل. \\
\hline 1 . & 1 & 1 & $\wedge$ & استخدام الخيوط القطنية في التطريز الثقيل. \\
\hline 1 . & 1 & 1 & $\wedge$ & استخدام الخيوط الحريرية في التطريز الثقيل. \\
\hline 1 . & 1 & - & 9 & استخدام الخيوط المعدنية في التطريز الثقيل. \\
\hline 1 . & - & - & 1 . & استخدام خيوط ذات سمك أكبر عند عمل الغرزة الخار جية للتصميم في التطريز الثقيل. \\
\hline 1. & - & - & 1 . & استخدام خيوط ذات سمك رفيع عند شغل الغرزة الداخلية في التصميم للتطريز الثقيل. \\
\hline 1. & - & - & 1. & استخدام طريقة العد لنقل التصميم الزخرفي على القماش في حالة التطريز الثقيل. \\
\hline 1. & 1. & - & - & استخدام ورق الكربون لنقل التصميم الزخرفي عبى القماش في حالة التطريز الثقيل. \\
\hline 1. & 1. & - & - & استخدام التخربم لنقل التصميم الزخرفي عبى القماش في حالة التطريز الثقيل. \\
\hline 1 . & r & - & $v$ & الثقيل. استخدام غرزة الستان لتحديد الشكل الخارجي للتص \\
\hline 1 . & $\wedge$ & - & r & | الزخر في علي القماش في التطريز \\
\hline 1 . & $\mathrm{v}$ & - & $r$ & استخيل إم غرزة البوان ستان لتحديد الشكل الخارجي للتصميم الزخرفي على القماش في التطريز \\
\hline 1 . & 1 & - & 9 & عليها التطريز المقصيل. الصغير ذو الطرف المدبب للتخلص من خيوط النسيج لتكوين الشبكة التي سيتم \\
\hline 1 . & $\wedge$ & - & r & استخا التطريز المقصقيل. الصغير ذو الطرف العريض للتخلص من خيوط النسيج لتكوين الشبكة التي سيتم \\
\hline 1 . & 9 & - & 1 & علستها التطريز الثقيل. الكبير ذو الطرف المدبب للتخلص من خيوط النسيج لتكوين الشبكة التي سيتم \\
\hline
\end{tabular}




$$
\text { رسالة ماجستير - كلية الاقتصاد المتزلي - جامعة المنوفية . }
$$

صفاء محمد نعمان عبد الوهاب ( 乞 . F ) : "استخدام أسلوبي الزخرفة

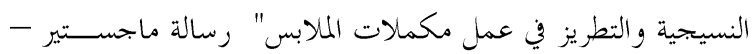

$$
\text { كلية الاقتصاد المترلي - جامعة المنوفية }
$$

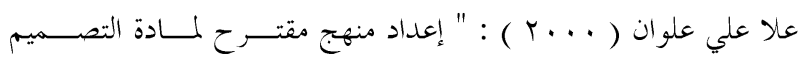
و التطريز لشعبة الملابس و النسيج وقياس فعاليته

: رسالة دكتوراه - كلية الاقتصاد المتزلي - جامعة حلوان .

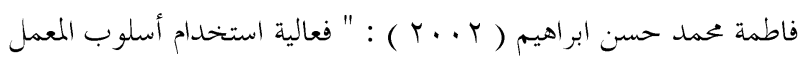

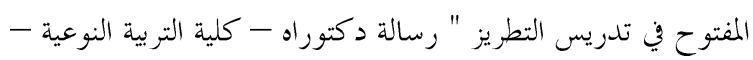

جامعة عين شمس .

ماجدة جريس حنين ( 1997 ) : " دراسات تحليلية لمطــرزات فتيــات

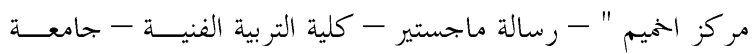

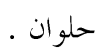

هناء رمزي علي " ب ... ץ " : اشغال الخياميــة - مكتبــة اليــسمين -

$$
\text { القاهرة . }
$$

.Sylvia Muir (2004 ) : " Classic Creations In Hardanger Embroidery. " Fargo - North Dakota .

Violet M.Endacott ( 2003 ) : "Design in Embroidery."

Bonaza - New York .

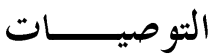

ا ـ توفير وإنتاج أقمشة تصلح لهذا الأسلوب من التطريسـز لنــــرة

$$
\text { وجورونا }
$$

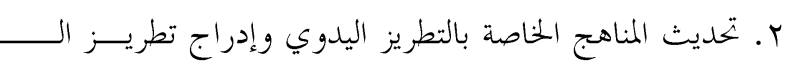

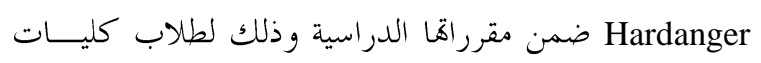
الاقتصاد المتزلي والتربية النوعية والكليات المناظرة .

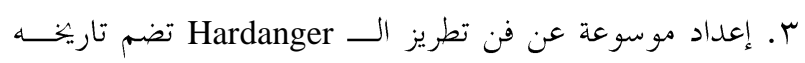

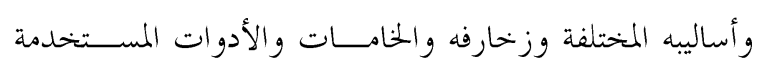

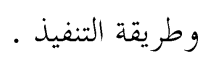

ع. التوسع في عمل الدورات التدريبية من خلال الجمعيات الأهلية

للفتيات المتسربات من التعليم او ذوي المؤهلات المتوسطة بفتح

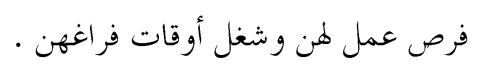

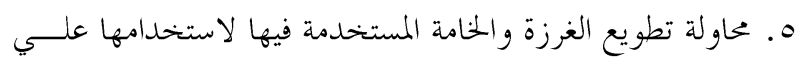
نطاق أوسع من المفروشات المترلية مثل استخدام الجلود وماشابه

$$
\begin{aligned}
& \text { كي تصلح لمكملات الزي وخحلافه . }
\end{aligned}
$$

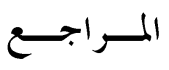

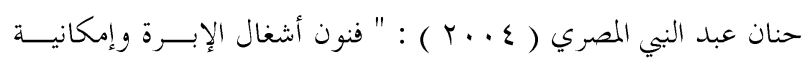

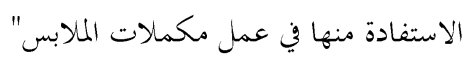




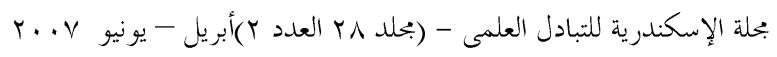

\title{
ABSTRACT \\ Applying of Hand Made Embroidery Style (Hardanger) on Some Upholstery Products designing a and The Execution and Evaluation of A Training Program for This Embroidery Style for a sample of trainers in Alexandria
}

\author{
Azza Ibrahim, Safia Sarokh and Anaam Abozeid
}

The main objective of this study was to revive the hardanger as a style of manual embroidery in order to use it and benefit from it in some textile products based in this technique such as upholstery .

This is in addition to designing and executing an applied training program of sample of women trainees in charge of training a group of young women ( tot ) on hardanger style .

An applied study was made through conducting some haranger experiments on materials using the thread subject of the study. Refereeing procedures were done through specialists in the field of textiles and clothes in general and specialist in the field of embroidery in particular ( 21 member ) ,this was conducted through a referring questionnaire that included several items . evaluation was carried out by giving a mark of (10) for each of the items .

An applied training program of this embroidery style was planned and executed for a sample of women trainers working in the field of training on small industries , that for (2) months then it was evaluated by measuring the awareness extent of trainers of knowledge and skills through using a prior post questionnaire .

As for the applied study models embroidered by hardanger of upholstery ( table cloth - curtain ) we referred and evaluated statistical relations of them were found by using variation test ant ( $\mathrm{T}$ ) test of the referring items of embroidered textile models and among all the three types of upholstery textiles in addition to the used embroidery threads and the effect of threads interference with textiles the statistical relations showed that :

\section{A-Table cloth :}

- The effect of the textiles was significant concerning item (1), (5) and (7) at the significant level (0.01)

- The effect of threads was significant for item (2) (5) and item (7)
- The effect of threads inference with the textiles was significant for item (5) and (7).

\section{According to (T) Text results :}

- Each of the textile 2/2 hopsack ( cotton $100 \%$ ) and 3/3 hopsack ( cotton $100 \%$ ) have obtained the highest evaluation marks .

- The highest evaluation degrees belonged to both standard cotton and pearl cotton .

- The textile $2 / 2$ hopsack ( cotton $100 \%$ ) and textile $3 / 3$ hopsack ( cotton $100 \%$ ) have obtained the highest evaluation degrees with both standard cotton and pearl cotton

\section{B- Curtain :}

- The effect of textile type was significant for each of item (1) , (5) and (7) at the significance level (0.01)

- The effect of threads type was significant on the items (2), (5) and (7) at the significance level (0.01) and (0.05) respectively .

- The effect of the threads interference with textiles was highly significant with item (5) and (7) at the significance level (0.01) and (0.05) .

According to $(\mathrm{T})$ test results :

- The material 2/2 hopsack ( cotton $100 \%$ ) has obtained the highest degree followed by $3 / 3$ hopsack ( cotton $100 \%$ )

- The standard cotton and pearl cotton threads obtained the highest evaluation degrees .

- Textile 2/2 hopsack ( cotton $100 \%$ ) with both standard cotton and pearl cotton has obtained the highest degree .

In regard to the results of the applied training program of hardanger it was revealed that most women subjects had experience in the training field about 1-5 years. Most of them did not have training courses in manual embroidery . Their informations about hardanger had changed positively after training . 